Article

\title{
FOXO1 Confers Maintenance of the Dark Zone Proliferation and Survival Program and Can Be Pharmacologically Targeted in Burkitt Lymphoma
}

\author{
Franziska Gehringer ${ }^{1}$, Stephanie E Weissinger ${ }^{2}$, Lotteke JYM Swier ${ }^{3}$, Peter Möller ${ }^{2}$, \\ Thomas Wirth ${ }^{1, *,+}$ and Alexey Ushmorov ${ }^{1, *,+}$ (i) \\ 1 Institute of Physiological Chemistry, University of Ulm, 89081 Ulm, Germany; \\ franziska.gehringer@uni-ulm.de \\ 2 Institute of Pathology, University of Ulm, 89081 Ulm, Germany; \\ weissinger.stephanie@googlemail.com (S.E.W.); peter.moeller@uniklinik-ulm.de (P.M.) \\ 3 Department of Pathology and Medical Biology, University of Groningen, 9747 AG Groningen, \\ The Netherlands; 1.j.y.m.swier@umcg.nl \\ * Correspondence: thomas.wirth@uni-ulm.de (T.W.); alexey.ushmorov@uni-ulm.de (A.U.); \\ Tel.: +49-731-500-23271 (T.W.); +49-731-500-33847 (A.U.); Fax: +49-731-500-22892 (T.W. \& A.U.) \\ $+\quad$ T.W. and A.U. share last authorship.
}

Received: 9 August 2019; Accepted: 20 September 2019; Published: 25 September 2019

\begin{abstract}
The FOXO1 transcription factor plays a central role in the proliferation and survival of B cells at several stages of differentiation. B cell malignancies, with exception of classical Hodgkin lymphoma, maintain expression of FOXO1 at levels characteristic for their non-malignant counterparts. Extensive expression profiling had revealed that Burkitt lymphoma (BL) show many characteristics of the dark zone (DZ) germinal center (GC) B cell program. Here we show that FOXO1 knockdown inhibits proliferation of human BL cell lines. The anti-proliferative effect of the FOXO1 knockdown is associated with the repression of the DZ B cell program including expression of MYB, CCND3, RAG2, $\mathrm{BACH} 2$, and CXCR4. In addition, the induction of signaling pathways of the light zone (LZ) program like NF- $\mathrm{KB}$ and PI3K-AKT was observed. Using a rescue experiment we identified downregulation of the proto-oncogene MYB as a critical factor contributing to the antiproliferative effect of FOXO1 knockdown. In an attempt to estimate the feasibility of pharmacological FOXO1 repression, we found that the small molecular weight FOXO1 inhibitor AS1842856 induces cell death and growth arrest in BL cell lines at low concentrations. Interestingly, we found that overactivation of FOXO1 also induces growth inhibition in BL cell lines, indicating the importance of a tight regulation of FOXO1 activity in BL.
\end{abstract}

Keywords: FOXO1; Burkitt lymphoma; germinal center dark zone B cell proliferation program

\section{Introduction}

Burkitt lymphoma (BL) is an aggressive B cell lymphoma [1] which originates from the germinal center (GC) [2], and is characterized by oncogenic translocations of the proto-oncogene MYC [3]. The GC consists of two main histological and functional compartments known as dark zone (DZ) and light zone (LZ). In the DZ, B cells undergo somatic hypermutation and actively proliferate and afterwards move to the $\mathrm{LZ}$ where they receive survival signals via the $\mathrm{B}$ cell receptor (BCR) and CD40 in case of successful recombination and expression of a high affinity antibody. The DZ gene expression program depends on expression of CCND3 and the transcription factors BCL6, FOXO1, and TCF3. In contrast, the DZ program is repressed by BCR and CD40 signaling [4] in LZ B cells. At the same 
time, signaling from the BCR and CD40 [4], which activate NF-KB, JAK-STAT, ERK, and PI3K-AKT pathways, is essential for survival and further differentiation of the LZ B cells [5-7].

Although MYC translocation under the control of immunoglobulin loci is an essential oncogenic event, it is not sufficient for BL progression. The maintenance of the main components of the DZ program [8] including physiologically high expression of FOXO1 [9] and TCF3 [1,10] is essential for BL. Moreover, activating mutations of TCF3 and FOXO1, inactivating mutations of TCF3 antagonist ID3, and protein stabilizing mutations of CCND3 belong to the most frequent oncogenic events in BL [10-12].

The FOXO family of transcription factors regulates multiple processes, including cell cycle progression, apoptosis, glucose metabolism, differentiation, protection from oxidative stress, and stem cell maintenance [13-15]. In some B cell malignancies, FOXO1 acts as a tumor suppressor and its activation induces growth arrest and apoptosis [13,16-18]. Surprisingly, FOXO1 knockdown in the MYC-PI3K driven mouse model of BL resulted in cell death and growth arrest [9]. Moreover, FOXO1 gene editing results in time-dependent selection of in-frame edited clones [9] and impedes proliferation of BL cell lines [19], indicating a role of FOXO1 in BL lymphomagenesis.

Using gene expression profiling (GEP), we found that FOXO1 knockdown, inter alia, represses DZ signature genes and this was associated with the activation of $\mathrm{LZ}$ signaling such as activation of PI3K-AKT and IKK-NF-KB pathways. Moreover, we demonstrated the feasibility of pharmacological inhibition of FOXO1 to mimic genetic FOXO1 down-regulation in BL as a potential therapeutic strategy.

\section{Results}

\subsection{FOXO1 Expression is Essential for BL Survival}

BL tumors maintain high levels of FOXO1, comparable to normal CD19+ B cells [20]. Since the activity of FOXO transcription factors is regulated by changing the nuclear localization of FOXOs, we used subcellular fractionation (Figure S1A) and immunofluorescent staining of FOXO1 in BL samples and cell lines to investigate whether FOXO1 is potentially active (Figure S1B,C, respectively). Given that occasional monoallelic mutations in an $\mathrm{N}$-terminal hotspot were suggested to confer FOXO1 insensitivity to AKT-dependent phosphorylation in BL, we included cell lines harboring both wild type (Ramos, BL-41, Daudi, Raji) and also mutated FOXO1 alleles (Namalwa, Jiyoye) (Table S1). Both methods identified a substantial fraction of FOXO1 in the nuclei, independently of its mutational status, supporting a role of active FOXO1 in the oncogenic program of BL.

Genomic editing of BL cell lines was shown to increase positive selection of in-frame edited clones in comparison to out-of-frame edited clones [9]. To find out whether acute depletion of FOXO1 has an antitumor effect in BL cell lines, we transduced BL cells with vectors expressing the fluorescent marker RFP and shRNAs targeting different FOXO1 sites (Figure 1A) and monitored the dynamic of the $\mathrm{RFP}^{+}$population (Figure 1B). F1sh specifically targeted FOXO1, whereas Fsh1/3/6 might in addition target FOXO3 and FOXO6, but preferentially downregulated FOXO1 expression [21,22]. The cHL cell lines L428 and U-HO1, which do not depend on FOXO1 [20,23], were used as negative controls. In all BLs, both shRNAs decreased the proportion of $\mathrm{RFP}^{+}$cells in comparison to cells transduced with the scrambled shRNA, independently of the FOXO1 mutational status (Table S1). In contrast, the cHL cell lines were insensitive to FOXO1 knockdown. In addition, we corroborated our results on the antitumor effect of FOXO1 knockdown using CRISPR/Cas9 genome editing (Figure 1C and Figure S2A-E).

To understand the mechanisms of the low performance of the FOXO1-depleted cells in the competitive proliferation assay, we analyzed the cell cycle distribution and induction of apoptosis. In two cell lines, FOXO1 knockdown induced $\mathrm{G}_{1}$-arrest, whereas in Ramos it slightly increased apoptosis (Figure 1D,E). Finally, to prove the specificity of the anti-proliferative effect of FOXO1 knockdown, we co-expressed the FOXO1 shRNA with a wild type FOXO1 harboring a wobbled F1sh target site (F1wob) in BL-41 and Ramos. We found that the expression of F1wob resulted in a significant protection of the cells from the knockdown of endogenous FOXO1 (Figure 1F,G). 



Figure 1. FOXO1 knockdown negatively regulates proliferation of BL cell lines. (A,B) BL and cHL cell lines were transduced with lentiviral vectors expressing FOXO1 shRNA (F1sh) or FOXO shRNA1/3/6 (Fsh1/3/6) vs. scrambled (scr) control. (A) Knockdown efficiencies of F1sh and Fsh1/3/6 vs. scr control. Transduced cells were selected for 2 days using $4 \mu \mathrm{g} / \mathrm{mL}$ puromycin and FOXO1 expression was analyzed 5-6 days post transduction. Expression of TUBB served as loading control. A representative of 2-3 independent experiments is shown. (B) Growth dynamics of transduced BL and cHL cell lines. The percentage of $\mathrm{RFP}^{+}$cells was measured every 3 days using flow cytometry starting from day 4 post 
transduction. The percentage of $\mathrm{RFP}^{+}$cells at begin of measurements (day 0) was set as 100 . Data are shown as mean \pm SD $(n \geq 3)$. (C) BL cell line Namalwa was transduced with lentiviral vectors co-expressing Cas9 with sgRNAs targeting FOXO1 (sgF1.1, sgF1.2) or non-targeting (NT) control. For constructs expressing sgRNAs, $\mathrm{RFP}^{+} / \mathrm{FOXO1}^{-}$cell population was tracked (Figure S1C). For $\mathrm{NT}$ control, $\mathrm{RFP}^{+} / \mathrm{FOXO1}{ }^{+}$cell population was tracked, due to the apparent absence of $\mathrm{RFP}^{+} / \mathrm{FOXO1}^{-}$population in this group. The samples were measured every 3 days by flow cytometry. First measurement was performed 4 days post transduction and the percentage of the indicated cell population was set as 100. Data are shown as mean \pm SD $(n=2)$. (D) FOXO1 knockdown inhibits cell cycle progression. BL cell lines expressing F1sh or scr vectors were sorted 4 days post transduction, followed by cell cycle analysis by PI staining. Data are shown as mean percentage of cells in a cell cycle phase $\pm \operatorname{SD}(n=3)$. The data were analyzed by two-sided T-test. ${ }^{*}, p<0.05,{ }^{* *}, p<0.01,{ }^{* * *}, p<0.001$. (E) Cell death analysis of BL cell lines expressing F1sh or scr. Transduced cells were sorted 4 days post transduction and incubated in complete medium for $48 \mathrm{~h}$ followed by Annexin V-FITC/PI staining. Specific Apoptosis (SA) was calculated as SA $(\%)=100 \times\left(A_{E}-A_{C}\right) /\left(100-A_{C}\right)$, where $A_{E}$ equals the percentage of apoptotic cells in the experimental group and $A_{C}$ equals the percentage of apoptotic cells in the control group. Data are shown as mean $\pm \mathrm{SD}(n=2)$. The data were analyzed by two-sided T-test. ${ }^{*}, p<0.05,{ }^{* * *}, p<0.001$. (F,G) BL cell lines were transduced with F1sh, with a vector expressing F1wob and F1sh (F1sh-F1wob), or with scr control. (F) Cells were sorted on day 4 and the expression of FOXO1 was analyzed by immunoblot. TUBB served as loading control. A representative of 2 independent experiments is shown. (G) The percentage of $\mathrm{RFP}^{+}$cells was measured every 3 days using flow cytometry. First measurement was performed $4-5$ days post transduction and the percentage of $\mathrm{RFP}^{+}$ cells was set as 100. Data are shown as mean $\pm \operatorname{SD}(n=3)$.

\subsection{FOXO1 Knockdown Inhibits the Expression of Core-Survival Genes in BL}

To understand the molecular mechanisms responsible for the antiproliferative effect of FOXO1 depletion in BL, we used gene expression profiling (GEP). Using a Human Gene 1.0 ST Affymetrix array, we first identified the top 20 genes concomitantly downregulated in BL-41 and Namalwa by the FOXO1 knockdown. Among them were the known FOXO1 targets CXCR4 [5] and RAG2 [24] as well as critical regulators of BL proliferation MYB, MAD2L1, and BUB1 [25-28] (Figure 2A and Table S2). Using qRT-PCR we validated the downregulation of $M Y B$ as well as FOXO1 target genes CCND3 [29,30], IRF4 [31], BACH2 [18,30,32], and DNA repair genes RAD51 and RAD51AP1 (Figure 2B).

Given that CCND3 contributes to the oncogenic program of BL [1], we analyzed its expression at the protein level after FOXO1 knockdown, but failed to reveal any modulation (Figure S3A). Moreover, co-transfection of CCND3 did not rescue BL-41 and Namalwa cell lines from the anti-proliferative effects of FOXO1 knockdown (Figure S3C,D), indicating that repression of CCND3 is not the key event for the anti-proliferative effects observed after FOXO1 knockdown. Given a role of FOXO1 in the protection against reactive oxygen species [14], we analyzed oxidative stress levels and expression of the mitophagy marker TOM20 after FOXO1 knockdown, but did not observe any effects either (Figure S4).

Using GSEA (Table S3) we identified proliferation-associated signatures, including cell cycle related targets of E2F transcription factors, G2/M checkpoint, and mitotic spindle assembly signatures (Figure S5A and Tables S4-S6). Furthermore, we detected a repression of FOXO1 target genes in GC B cells signature [5] (Figure S5D and Table S7-S9 and Table S20) upon FOXO1 knockdown. The signatures of core-survival BL genes [33] (Figure S5B and Table S10, Table S11 and Table S19) including MYB [27] (Table S12) (Figure 2C) were also significantly repressed. We validated MYB downregulation at the protein level (Figure 2D) and corroborated the previously shown essential role of MYB in BL maintenance [26,27] using shRNA knockdown (Figure 2E,F). Finally, we confirmed the role of MYB repression in the antitumor effect of FOXO1 depletion by a rescue experiment. Overexpression of the full-length $100 \mathrm{kDa}$ version of $M Y B$, which is expressed by BL cells in addition to the $75 \mathrm{kDa}$ splice variant and shares similar properties [34], protected BLs from the antiproliferative effect of FOXO1 knockdown (Figure $2 \mathrm{G}, \mathrm{H}$ ) by relieving the $\mathrm{G}_{1}$-arrest (Figure $\mathrm{S} 6$ ).

Thus, FOXO1 is essential for the expression of core survival genes in BL including MYB. 
A

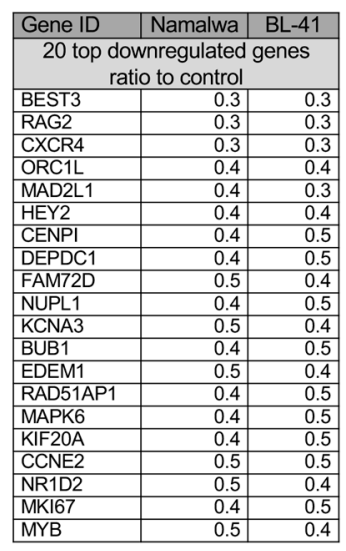

C

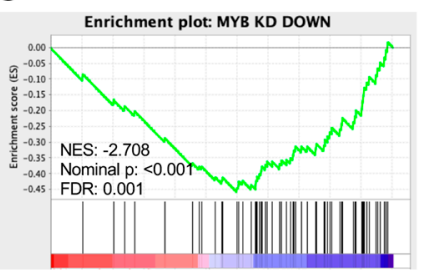

E

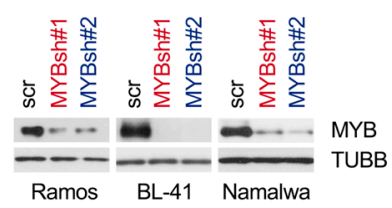

G

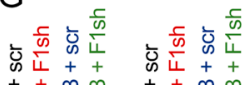

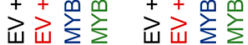

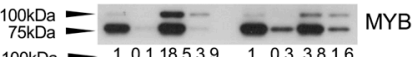

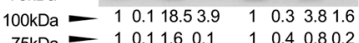

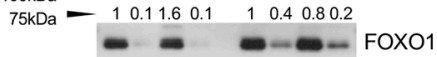

$\frac{----}{\mathrm{BL}-41} \frac{---- \text { TUBB }}{\text { Namalwa }}$
B

FOXO1

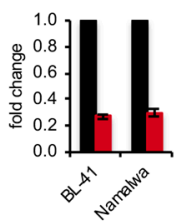

CCND3
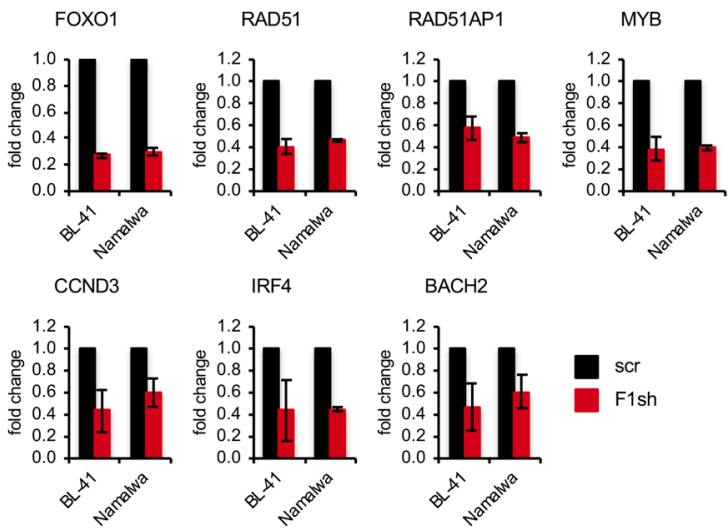

IRF4
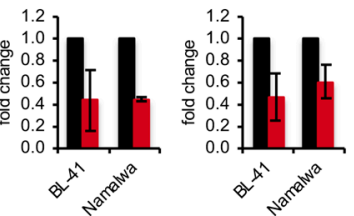

D

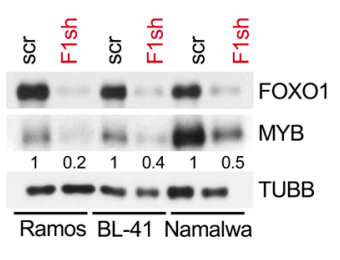

F
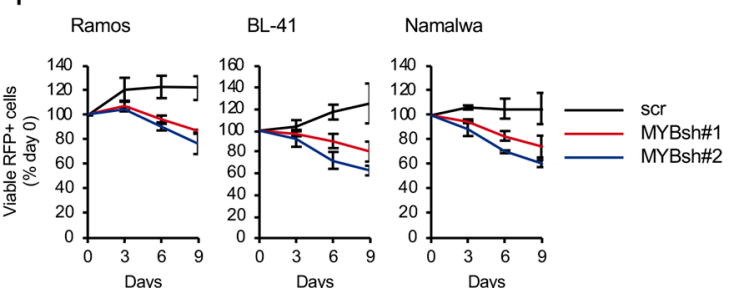

$\mathrm{H}$
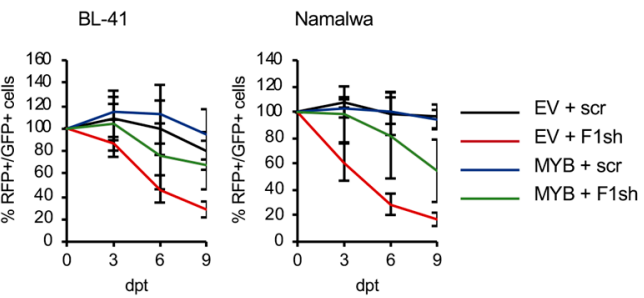

Figure 2. Mechanism of the anti-tumor effect of FOXO1 knockdown. (A) Top 20 genes downregulated after FOXO1 knockdown > 1.5-fold in both cell lines. BL cell lines expressing F1sh or scr control were harvested on day 4 after transduction for gene expression profiling using Human Gene 1.0 ST Affymetrix GeneChip array. Analysis of raw data was done using Genesifter software (RMA normalization, centered Pearson correlation, coefficient 0.98) $(n=2)$. (B) Validation of the GEP. The effect of FOXO1 knockdown on the expression of indicated genes was validated by qRT-PCR. qRT-PCR data were quantified by the $2^{-\Delta \Delta \mathrm{CT}}$ method. Data are shown as mean $\pm \mathrm{SD}(n=2)$. The data were analyzed by two-sided T-test. For all genes and cell lines $p<0.05$. (C) GSEA. MYB depletion signature is repressed by FOXO1 knockdown (Table S12). Direction of phenotype comparison: "F1sh vs. scr". Gene signature "MYB KD DOWN" [27] comprises genes downregulated by MYB knockdown with $p<0.05$ (Table S18) and was applied on set of genes modulated more than 1.5-fold by FOXO1 knockdown (threshold of 1.5, ANOVA, Benjamini and Hochberg correction, adjusted $p<0.05)$. NES: Normalized enrichment score. FDR: False discovery rate. (D) BL cells transduced with F1sh and scr vectors were selected for 2 days using $4 \mu \mathrm{g} / \mathrm{mL}$ puromycin, and MYB expression was analyzed by immunoblot. TUBB served as loading control. A representative of 2 independent experiments is shown. Densitometric quantification of MYB/ 
MYB/TUBB protein levels was done with ImageJ software (https://imagej.nih.gov/ij/, RRID: SCR_003070). (E,F) BL cell lines were transduced with vectors expressing MYB shRNAs (MYBsh\#1, MYBsh\#2) or scr control. (E) Cells were selected for 2 days using $4 \mu \mathrm{g} / \mathrm{mL}$ puromycin and MYB expression was analyzed by immunoblot. Expression of TUBB serves as loading control. A representative of 2 or 3 independent experiments is shown. (F) Growth dynamics of transduced BL cell lines. The percentage of $\mathrm{RFP}^{+}$cells was measured every 3 days using flow cytometry. First measurement was performed 4 days post transduction and the percentage of $\mathrm{RFP}^{+}$cells was set as 100 . Data are shown as mean $\pm \mathrm{SD}$ $(n \geq 3)$. (G,H) Expression of MYB rescues BL from inhibition of proliferation induced by FOXO1 knockdown. BL cell lines expressing MYB or empty vector (EV) were transduced with F1sh vs. scr control. (G) $\mathrm{GFP}^{+} / \mathrm{RFP}^{+}$cells were sorted on day 5 and the expression of FOXO1 and MYB was analyzed by immunoblot. TUBB served as loading control. A representative of 2 independent experiments is shown. Please note that the transduced full length MYB ORF (100 kDa) [35] is also present in not transduced cells. Densitometric quantification of $75 \mathrm{kDa}$ MYB/TUBB and $100 \mathrm{kDa}$ MYB/TUBB protein levels was done with ImageJ software (https://imagej.nih.gov/ij/, RRID: SCR_003070). (H) The percentage of $\mathrm{GFP}^{+} / \mathrm{RFP}^{+}$cells was measured every 3 days using flow cytometry. First measurement was performed $4-5$ days post transduction and the percentage of $\mathrm{RFP}^{+}$cells was set as 100 . Data are shown as mean $\pm \operatorname{SD}(n=3)$.

\subsection{FOXO1 Is Critical for Maintenance of the DZ Phenotype and for Control of the NF-KB and PI3K-AKT} Activity in $B L$

Given an essential role of FOXO1 in maintenance of the DZ program $[1,6]$, we applied gene expression signatures of human tonsillar DZ $\left(\mathrm{CXCR}^{+}\right)$and $\mathrm{LZ}\left(\mathrm{CXCR} 4^{-}\right)$cells $[36,37]$ to the FOXO1 knockdown signature. We found that FOXO1 depletion significantly repressed the DZ signature and enriched the LZ signature (Figure 3A and Tables S13 and S14; Figure S5C and Tables S15 and S16). Since BL depends on the DZ survival and proliferation program $[1,2,37,38]$, we analyzed the expression of the DZ marker CXCR4 after FOXO1 repression by flow cytometry (Figure 3B). We observed a strong downregulation of CXCR4 in cells transduced with the FOXO1 shRNA, but not in cells expressing the control vector. In addition, the isotype control was not altered. Given that the decrease of CXCR4 on the cell surface measured by the fluorochrome-coupled antibody might be explained by activation-induced CXCR4 internalization [39], we analyzed CXCR4 expression by immunoblot. We found a strong decrease of CXCR4 expression. This supports the concept of transcriptional repression as the important mechanism (Figure 3C). Finally, to exclude the possibility that the observed downregulation of GC DZ genes represents an shRNA off-target effect we corroborated the results of FOXO1 knockdown by FOXO1 genome editing. Using immunoblot, we found that both sgRNAs downregulated the expression of CXCR4 and MYB in the BL cell line Namalwa (Figure S2D).

As activation of NF- $\kappa$ B contributes to the LZ program [37], we applied a "NF- $\mathrm{B}$ activation in BL" signature [40] and found its significant enrichment after FOXO1 knockdown (Figure 3A and Table S17). NF- $\mathrm{BB}$ activation was proven by an increase of IKK-dependent RELA/p65 phosphorylation at the S536 residue (Figure 3D) and by induction of a NF- $k B$-responsive luciferase reporter construct (Figure 3E).

PI3K-AKT activity is also higher in LZ than in DZ B cells [5,6]. We therefore analyzed the AKT phosphorylation status and observed an increase of the $\mathrm{pAKT}^{\mathrm{T} 308}$ signal by the FOXO1 knockdown (Figure 3F). We conclude that FOXO1 contributes to the maintenance of the DZ program by inducing CXCR4 and MYB and via attenuation of the IKK-NF- $\mathrm{B}$ and AKT activity in BL. 
A

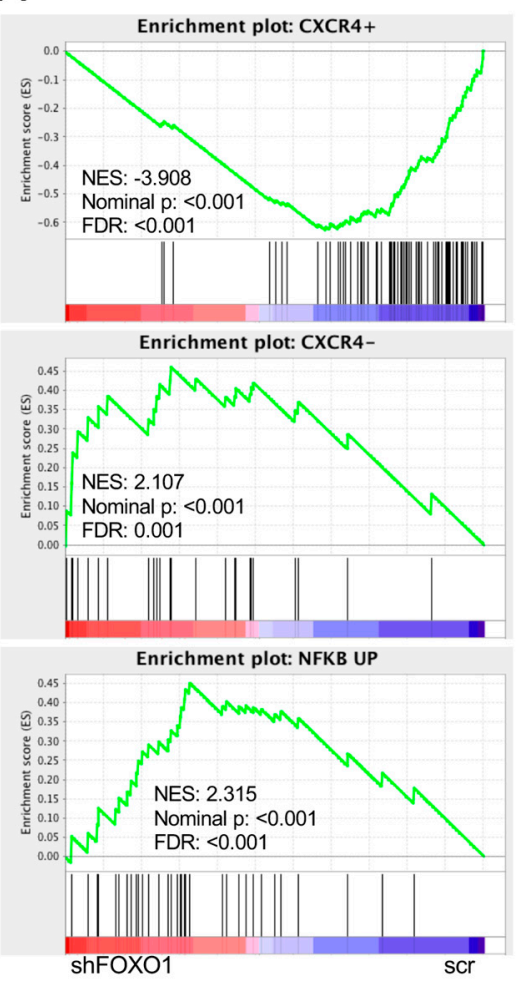

B

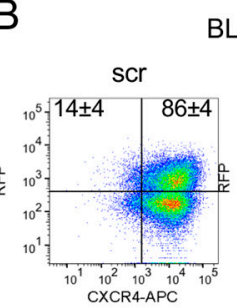

BL-41

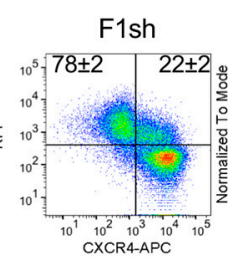

$\square$ scr $\square$ FOXO1 shRNA
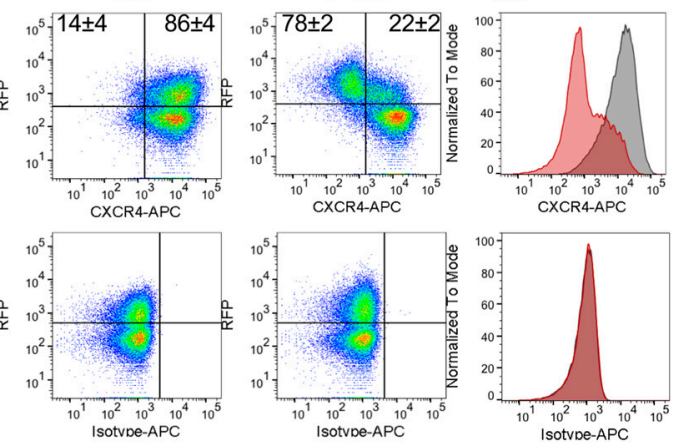

Namalwa

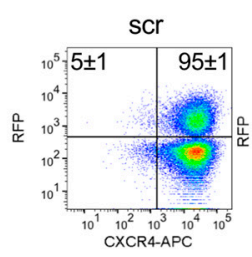

F1sh
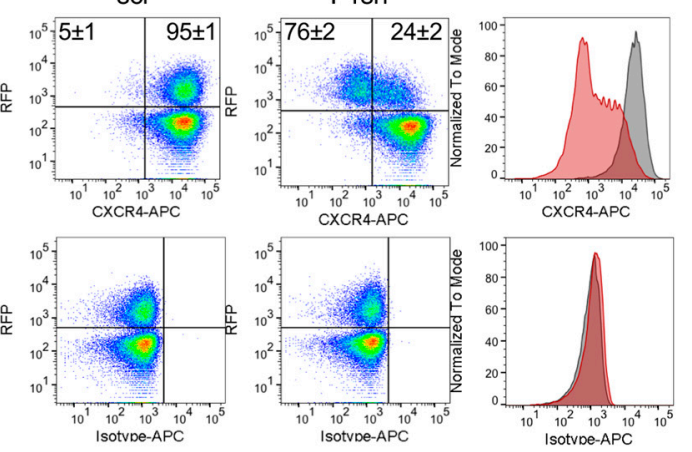

C

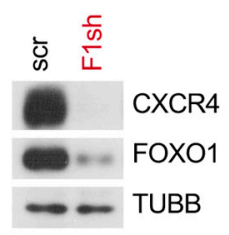

D

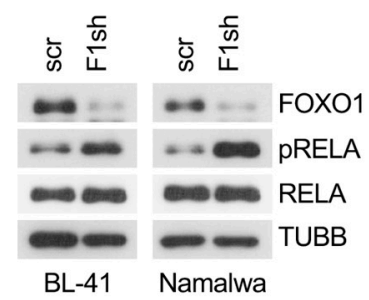

E

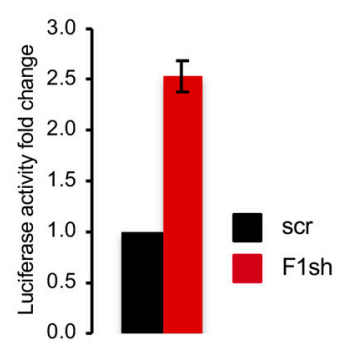

F

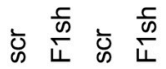

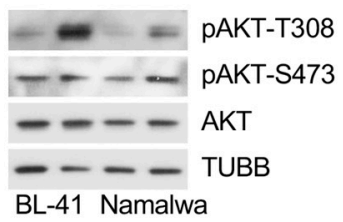

Figure 3. FOXO1 knockdown induces loss of the DZ program and PI3K-AKT and IKK-NF-KB activation. (A) GSEA. Gene signatures comprising genes differentially expressed genes in $\mathrm{CXCR} 4^{+}$centroblasts vs. CXCR4 ${ }^{-}$centrocytes [36] and gene signature comprising genes differentially expressed in Ramos cell line transfected with constitutively active CA-IKK2 vs. EV control [40] were applied on set of genes modulated more than 1.5 fold by FOXO1 knockdown (threshold of 1.5, ANOVA, Benjamini and Hochberg correction, adjusted $p<0.05$ ). Direction of phenotype comparison: "F1sh vs. scr" (Tables S13, S14, S17). (B) F1sh downregulates CXCR4. BL cell lines expressing F1sh or scr control were stained with CXCR4-APC or isotype control 7 days post transduction. Dot-plots show percentages of CXCR4 ${ }^{+} / \mathrm{RFP}^{+}$ 
and $\mathrm{CXCR} 4^{-} / \mathrm{RFP}^{+}$cells. For histograms, only transduced $\mathrm{RFP}^{+}$cells were included. Data are shown as mean $\pm \mathrm{SD}(n=3)$. (C) BL-41 cell line expressing F1sh or scr control was FACS sorted 4 days post transduction and CXCR4 levels were analyzed by immunoblot. TUBB served as loading control. A representative of 2 independent experiments is shown. (D) FOXO1 knockdown activates IKK. BL cell lines expressing F1sh or scr control were sorted 4 days post transduction and phosphorylation status of RELA ${ }^{\text {S536 }}$ (IKKs target), and total RELA were analyzed by immunoblot. TUBB served as loading control. A representative of 2 independent experiments is shown. (E) Luciferase reporter assay using the Namalwa cell line stably expressing a NFkB-dependent luciferase reporter ( $3 \times \kappa$ B.luc) [41]. Cells were transduced with F1sh followed by FACS sorting for RPF 4 days post transduction and cell lysis. Luminescence was measured as described in Supplemental Methods. Data are shown as mean \pm SD $(n=3)$. (F) BL cell lines expressing F1sh or scr control were FACS sorted 7 days post transduction and $\mathrm{pAKT}^{\mathrm{T} 308}$ and $\mathrm{pAKT}^{\mathrm{S} 473}$ levels were analyzed by immunoblot. TUBB served as loading control. A representative of 2 independent experiments is shown.

\subsection{Pharmacologic FOXO1 Inactivation Inhibits Proliferation and Induces Apoptosis in BL Cell Lines}

Recently, we revealed the cytotoxic activity of a small molecular weight FOXO1 inhibitor AS1842856 against BCP-ALL in in vitro, ex vivo, and in vivo models [21]. Therefore, we measured the sensitivity of BL cell lines to the inhibitor (Figure 4A). As sensitivity burden we chose $300 \mathrm{nM}$, which is the plasma concentration of AS1842856 in mice after oral administration in an experimental anti-diabetic treatment [42]. This concentration has been proven to have a robust antitumor effect against BCP-ALL patient-derived xenotransplants in vivo [21]. Four of six BL cell lines were sensitive to the inhibitor ( $\mathrm{IC}_{50}$ values between 2 and $94 \mathrm{nM}$ ). Moreover, AS1842856 induced CASP3 cleavage (Figure 4B), which was associated with apoptosis in two of three cell lines (Figure 4C) and $\mathrm{G}_{1}$-cell cycle arrest (Figure 4D). The inhibitor downregulated transcription of FOXO1 targets similar to FOXO1 knockdown (Figure 4E). AS1842856 also induced RELA ${ }^{\mathrm{S} 536}$ phosphorylation and NF-kB-dependent transcription (Figure 5A,B). Moreover, it downregulated MYB expression and induced $\mathrm{AKT}^{\mathrm{T} 308}$ as well as $\mathrm{AKT}^{\mathrm{S} 473}$ phosphorylation (Figure 5A,C, respectively). Similar to FOXO1 knockdown using the shRNA, AS1842856 treatment resulted in a strong CXCR4 repression (Figure 5D,E). In contrast to the genetic FOXO1 repression, pharmacologic FOXO1 inactivation also repressed CCND3 at the protein level, independently of its CCND3 mutational status (Figure 5F and Figure S3B). Interestingly, MYB overexpression completely rescued BL cells from the cytotoxic effect of the inhibitor (Figure 5G,H), indicating that MYB downregulation is a crucial factor in the toxic effect of AS1842856.

Surprisingly, and in contrast to the genetic knockdown, AS1842856 did not inhibit MYB transcription (Figure 6A). The downregulation of MYB at protein level could further not be explained by the increase of protein degradation (Figure 6B). It had been shown that MYB levels are attenuated by miR-150, a micro RNA downregulated in BL [43]. Thus, we explored the influence of AS1842856 on the expression of miR-150 and found that AS1842856 strongly induced miR-150 in BL cell lines (Figure 6C). With help of a CRISPR/Cas9-mediated miR-150 knockout construct, we demonstrated that miR-150 knockout protects BL cell lines from AS1842856-induced MYB downregulation (Figure 6D-F), indicating that AS1842856 downregulates MYB proteins levels by inducing the MYB-targeting miR-150. At present, the divergent mechanism by which genetic and pharmacological interference with FOXO1 affect MYB are not completely understood.

Nevertheless, pharmacologic FOXO1 inhibition mimics the effects of genetic FOXO1 downregulation. 

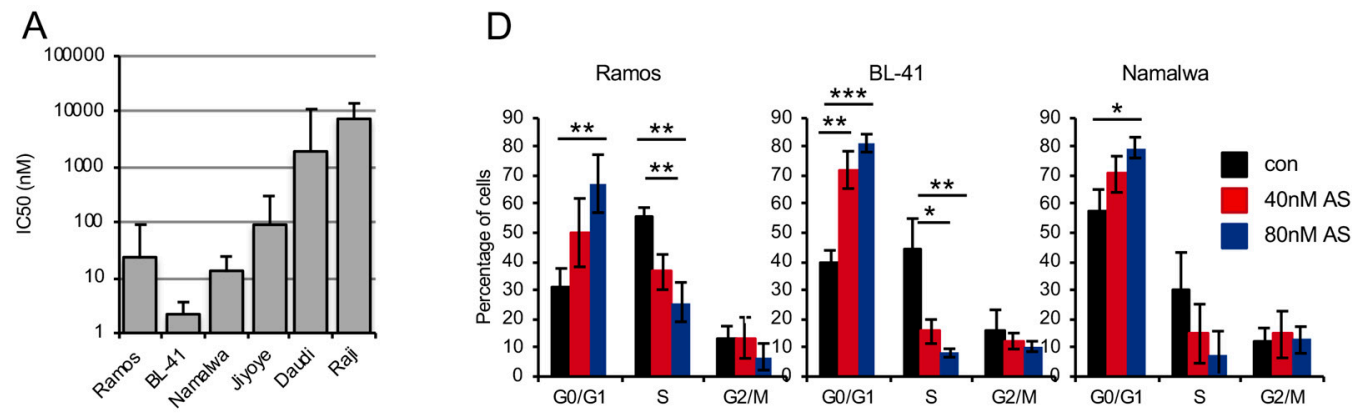

\section{B}

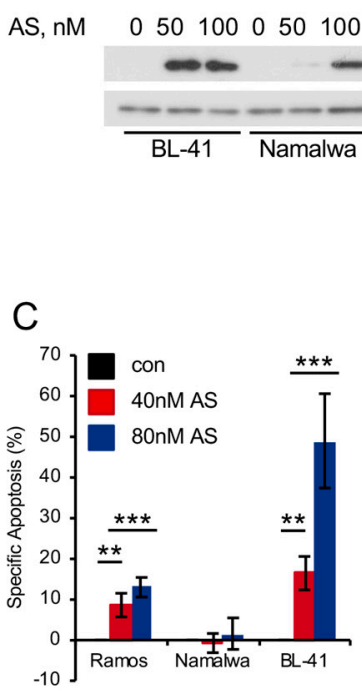

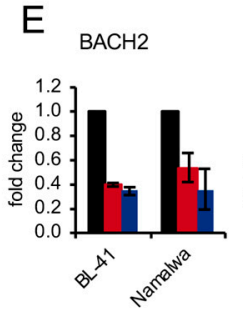

RAD51

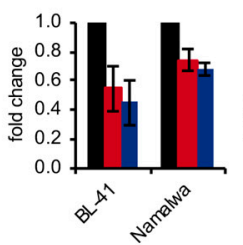

AICDA

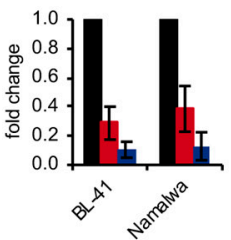

RAD51AP1

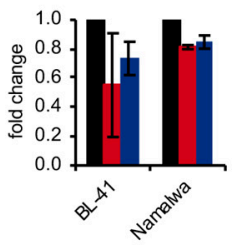

CCND3

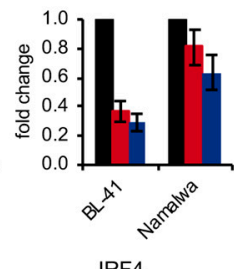

IRF4

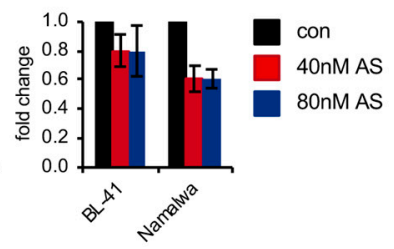

Figure 4. AS1842856 treatment is toxic for BL cell lines. (A) Sensitivities of BL cell lines to FOXO1 inhibitor AS1842856 (AS). Cells were exposed to increasing concentrations of AS for 5 days. Cell viability was assessed using MTT assay and IC50 values were calculated using GraphPad Prism software. Data are shown as mean $\pm \mathrm{SD}(n=3)$. (B) Cleaved CASP3 was detected in BL cell lines treated with AS or DMSO for 4 days using immunoblot. TUBB served as loading control. A representative of 3 independent experiments is shown. (C) AS induces apoptosis in BL cell lines. Cells were treated for 4 days with AS or DMSO, followed AnnexinV-FITC/PI staining. Data are shown as mean of specific apoptosis $\pm \mathrm{SD}(n=2)$. The data were analyzed by two-sided T-test. ${ }^{* *}, p<0.01,{ }^{* * *}, p<0.001$. (D) AS inhibits cell cycle progression. Cells were incubated in the presence of AS or DMSO for 4 days, followed by fixation and PI staining. After FACS measurement percentage of cells in different cell cycle phases was assessed and is shown as mean $\pm \operatorname{SD}(n=3)$. The data were analyzed by two-sided T-test. ${ }^{*}, p<0.05,{ }^{* *}, p<0.01,{ }^{* * *}, p<0.001$. (E) Downregulation of FOXO1 target genes after treatment with AS compared to DMSO-treated cells. Treated cells were harvested after $24 \mathrm{~h}$ and RNA expression levels were analyzed by qRT-PCR. qRT-PCR data were quantified by the $2^{-\Delta \Delta C T}$ method. Data are shown as mean $\pm \mathrm{SD}(n=3)$. The data were analyzed by two-sided T-test. For all genes and cell lines $p<0.05$ with exception of Namalwa $+40 \mathrm{nM}$ AS CCND3 $p=0.051$; BL-41 + $40 \mathrm{nM}$ AS RAD51AP1 $p=0.136$. 
A

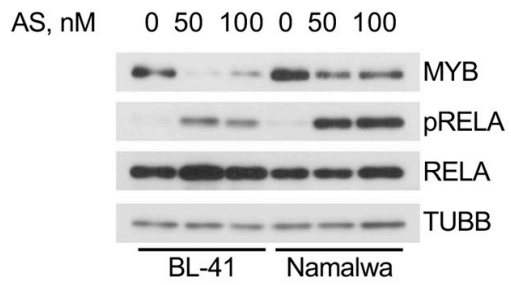

C
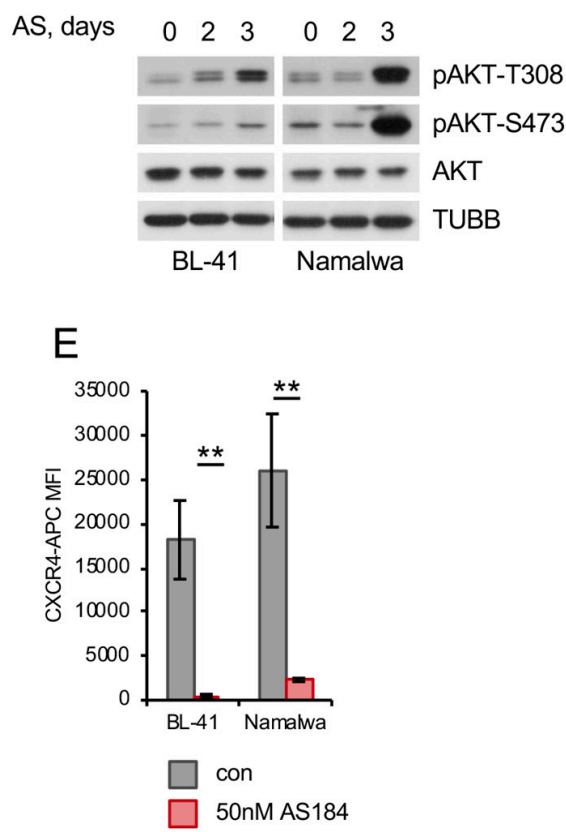

G

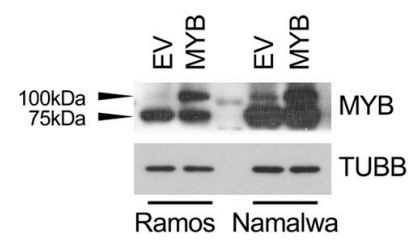

B

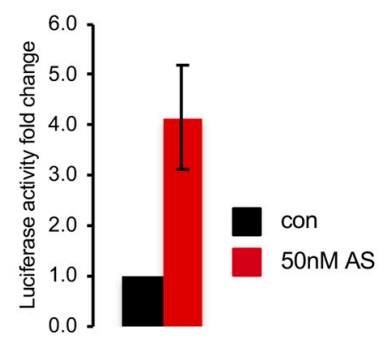

$\mathrm{D}$
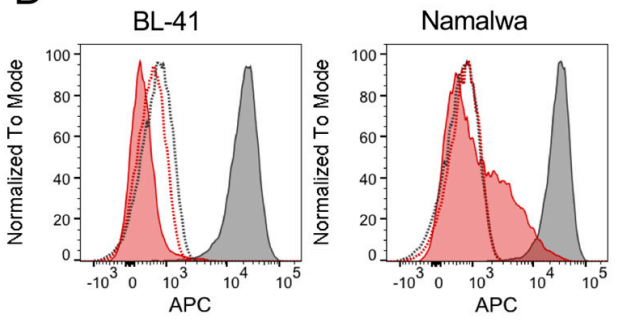

con CXCR4-APC

$\square$ 50nM AS CXCR4-APC

I-) con Isotype-APC

I.] 50nM AS Isotype-APC

$\mathrm{F}$

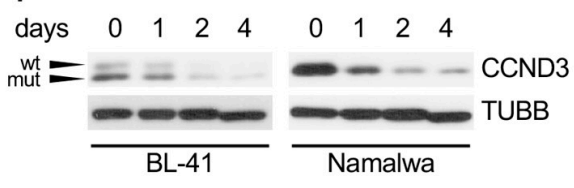

$\mathrm{H}$

Ramos

Namalwa
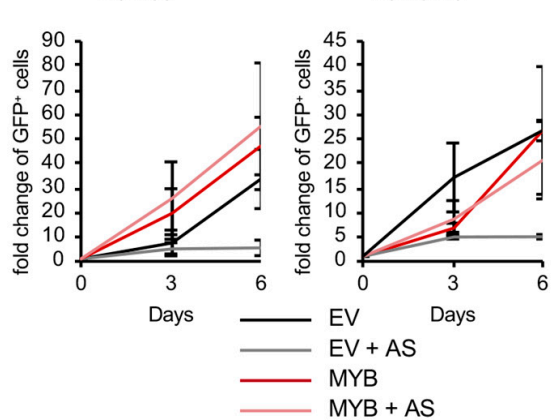

Figure 5. AS1842856 treatment mimics genetic FOXO1 inhibition. (A) Immunoblot showing reduced MYB and increased pRELA ${ }^{5536}$ levels after AS treatment for 4 days compared to DMSO-treated cells. TUBB served as loading control. Same loading control as in Figure 4B was used, since the same membrane was probed. A representative of 3 independent experiments is shown. (B) Luciferase reporter assay using the Namalwa cell line stably expressing a NF- $\mathrm{kB}$-dependent luciferase reporter (3× kB.luc) [41]. Cells were treated with $50 \mathrm{nM}$ AS for 3 days followed by cell lysis. Luminescence was measured as described in Supplemental Methods. Data are shown as mean $\pm \mathrm{SD}(n=3)$. (C) Immunoblot showing $\mathrm{pAKT}^{\mathrm{T} 308}$ and $\mathrm{pAKT}{ }^{\mathrm{S} 473}$ levels after 2 and 3 days of AS treatment compared to DMSO-treated cells. TUBB served as loading control. A representative of 2 independent experiments is shown. (D,E) AS downregulates CXCR4. BL cell lines were treated for 4 days with $50 \mathrm{nM}$ AS or DMSO. Treated cells were stained with CXCR4-APC or isotype control. (D) FACS histogram plots of stained cells. Data 
are shown as mean $\pm \mathrm{SD}(n=3)$. (E) Mean fluorescence intensity (MFI) of CXCR4-APC signal of AS-treated DMSO-treated cells. Data are shown as mean \pm SD $(n=3)$. The data were analyzed by two-sided T-test. ${ }^{* *}, p<0.01$. (F) AS decreases CCND3 protein level. BL cell lines were treated for up to 4 days with AS or DMSO and CCND3 levels were analyzed by immunoblot. Arrows indicate wild type and mutated version of CCND3 in BL-41. TUBB served as loading control. A representative of 2 independent experiments is shown. $(\mathbf{G}, \mathbf{H})$ MYB expression rescues BL cell lines from the toxic effect of AS. BL cell lines were transduced with lentiviral vectors expressing MYB vs. empty vector (EV) control. (G) Transduced cells were FACS sorted 4-5 days post transduction and MYB expression was analyzed. TUBB served as loading control. A representative of 2 independent experiments is shown. (H) Cells were treated with $100 \mathrm{nM}$ AS vs. DMSO control. Percentages of $\mathrm{GFP}^{+}$cells (by flow cytometry) and the total number of live cells (by cell counting) were measured at indicated time points. Data are shown as fold changes normalized to the initial number of live $\mathrm{GFP}^{+}$cells. The number of live $\mathrm{GFP}^{+}$cells was calculated as $n \mathrm{X} \% \mathrm{GFP}^{+}$cells/100, where $n$ is the number of live cells per well and $\% \mathrm{GFP}^{+}$is the percentage of $\mathrm{GFP}^{+}$cells. Data are shown as mean $\pm \mathrm{SD}(n \geq 3)$.

\section{A}



B
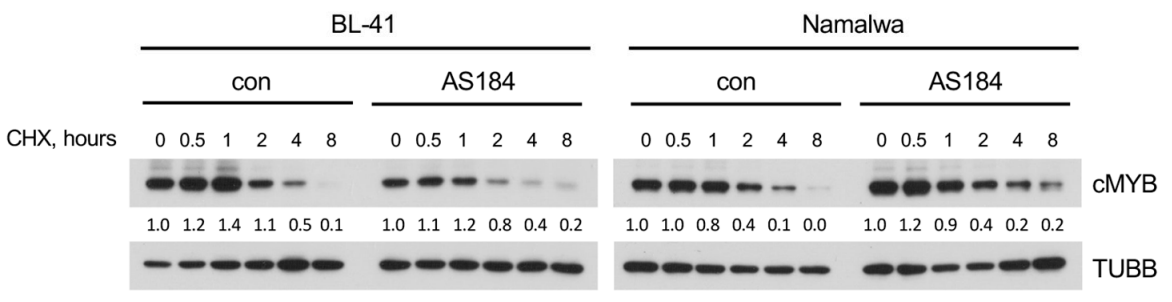

C
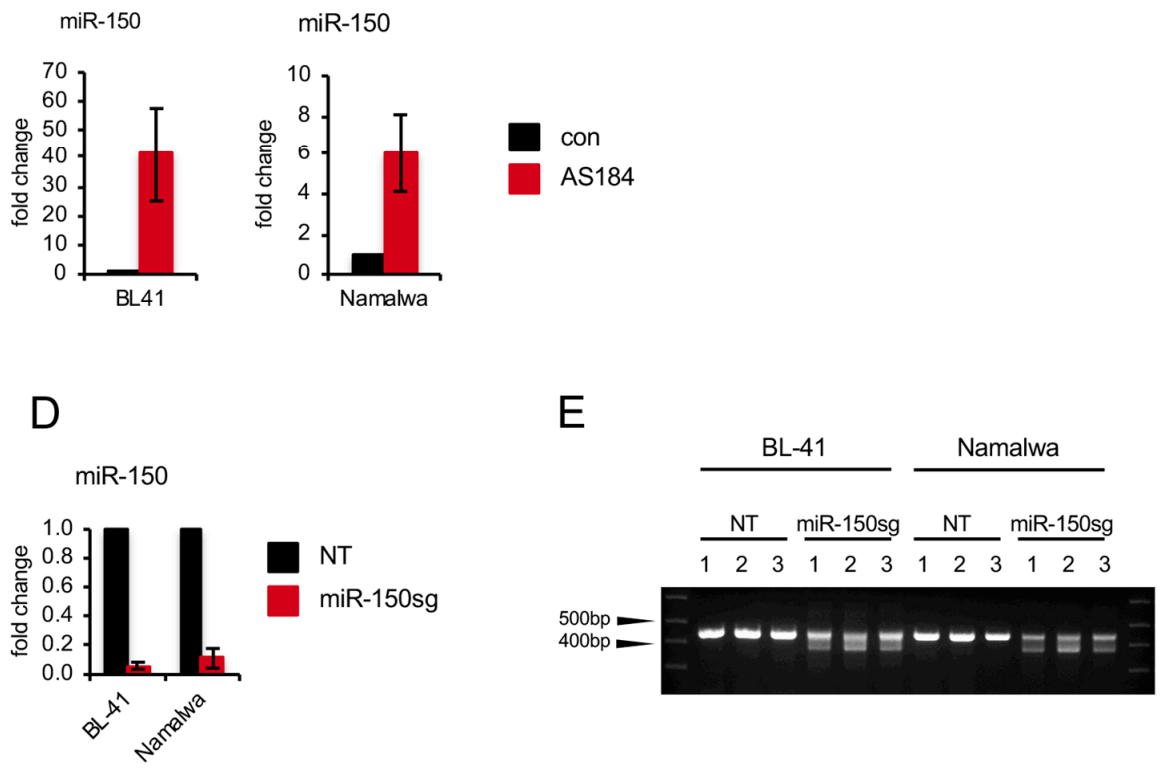

Figure 6. Cont. 


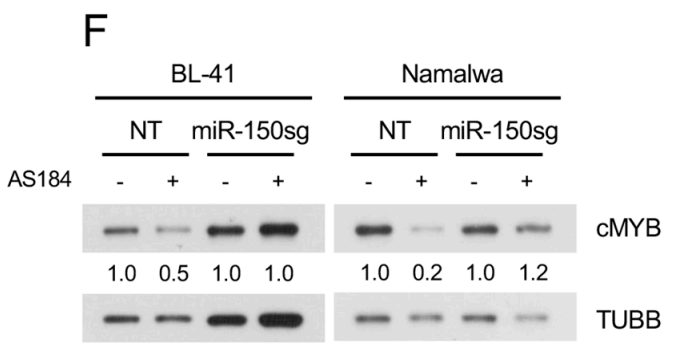

Figure 6. AS1842856 regulates MYB through upregulation of miR-150 (A) AS does not reduce MYB RNA levels. BL cells were treated with AS or DMSO. Treated cells were harvested after $24 \mathrm{~h}$ and RNA expression levels were analyzed by qRT-PCR. qRT-PCR data were quantified by the $2^{-\Delta \Delta C T}$ method. Data are shown as mean $\pm \mathrm{SD}(n=3)$. (B) AS does not induce MYB protein degradation. BL cells were treated with $10 \mu \mathrm{g} / \mathrm{mL}$ CHX and harvested 0-8 h later. Expression of MYB was analyzed by immunoblot. Expression levels of TUBB served as loading control. A representative of 2 independent experiments is shown. Densitometric quantification of MYB/TUBB protein levels was done with ImageJ software (https://imagej.nih.gov/ij/, RRID: SCR_003070). (C) AS induces miR-150 transcription. BL cells were treated with AS or DMSO. Treated cells were harvested after 3 days, followed by miRNA isolation and miRNA cDNA generation as described in Supplemental Methods. miRNA expression levels were analyzed by qRT-PCR. qRT-PCR data were quantified by the $2^{-\Delta \Delta C T}$ method. Data are shown as mean $\pm \mathrm{SD}(n=3)$. (D-F) BL cell lines were transduced with lentiviral vectors expressing a miR-150 CRISPR/Cas9 knockout construct or a non-targeting control (NT) and FACS sorted. (D) miRNA was isolated and miRNA cDNA was generated 4 days post transduction as described in Supplemental Methods. miRNA expression levels were analyzed by qRT-PCR. qRT-PCR data were quantified by the $2^{-\triangle \Delta C T}$ method. Data are shown as mean $\pm \mathrm{SD}(n=3)$. (E) miR-150 knockout construct is functional. Genomic DNA was isolated 4 days post transduction and the miR-150 locus was amplified as described in Supplemental Methods $(n=3)$. (F) miR-150 knockout rescues MYB levels in BL cell lines treated with AS. Cells expressing miR-150sg or NT con were treated with AS for 7 days. Expression of MYB was analyzed by immunoblot. Expression levels of TUBB served as loading control. A representative of 2 independent experiments is shown. Densitometric quantification of MYB/TUBB protein levels was done with ImageJ software (https://imagej.nih.gov/ij/, RRID: SCR_003070).

\subsection{Genetic FOXO1 Hyperactivation is Toxic for BL}

Previous studies by us and others had indicated that FOXO1 activity needs to be maintained in a strictly regulated range and both, too little as well as too much is bad for these tumors (Goldilocks principle) [21,23]. Given that genetic and pharmacological activation of FOXO1 induce apoptosis in different B cell lymphomas [13,16-18], we overexpressed an AKT-resistant inducible version of FOXO1 (FOXO1(3A)ER) (Figure 7A) in BL-41 and Namalwa BL cell lines. FOXO1(3A) ER activation inhibited

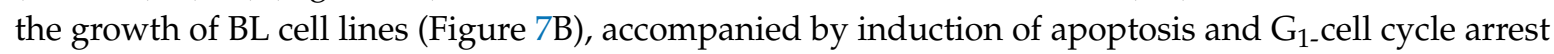
(Figure 7C,D, respectively). Consistently, we observed an upregulation of the pro-apoptotic FOXO1 target gene TNSF10/TRAIL (Figure 7E), CASP3 cleavage, and increase of cyclin-dependent kinase inhibitor CDKN1B (Figure 7A). Importantly, overexpression of wild type FOXO1 also inhibited the growth of BL cell lines (Figure 7F,G).

We conclude that both down- and up-regulation of FOXO1 activity negatively influence the survival and proliferation of BL, indicating that, similar to BCP-ALL [21], FOXO1 acts as a rheostat in the oncogenic program of this utmost aggressive lymphoma. 


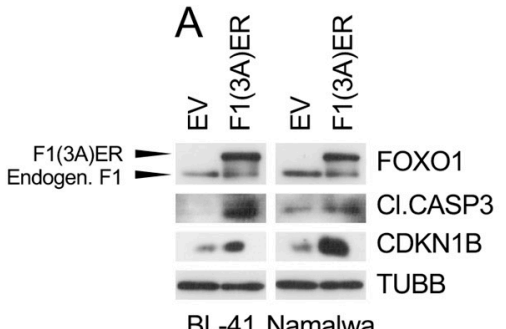

BL-41 Namalwa
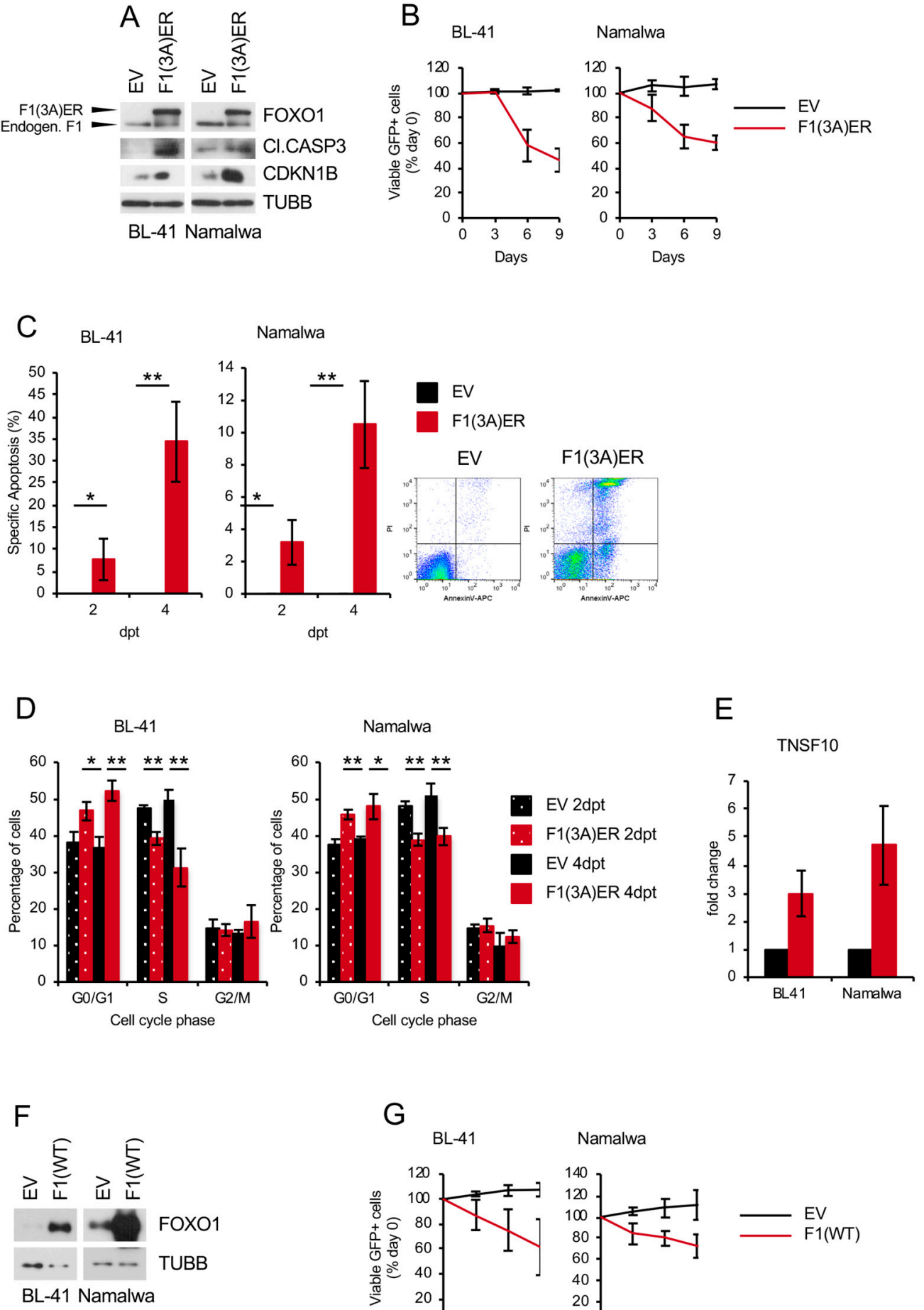

G
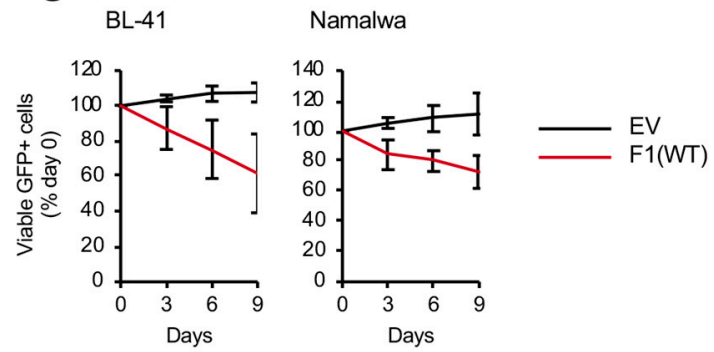

Figure 7. FOXO1 induces growth inhibition in BL cell lines (A-E) BL cell lines were transduced with lentiviral vectors expressing constitutively active FOXO1(3A) ER (F1ER) vs. empty vector (EV) control. (A) Transduced cells were FACS sorted and lysed 2 days post induction with $100 \mathrm{nM} 4$-OHT. Expression levels of FOXO1, cleaved CASP3 and CDKN1B were analyzed by immunoblot. TUBB served as loading control. A representative of 3 independent experiments is shown. (B) Growth dynamics of transduced BL cell lines. The percentage of $\mathrm{GFP}^{+}$cells was measured every 3 days using flow cytometry. First measurement was performed 4 days post transduction and the percentage of $\mathrm{GFP}^{+}$cells was set as $100 \%$. Data are shown as mean \pm SD $(n \geq 3)$. (C) Cell death analysis of BL cell lines. Transduced cells 
were FACS sorted, followed by AnnexinV-APC/PI staining 2- and 4-days post induction with $100 \mathrm{nM}$ 4-OHT. After FACS measurement, Specific Apoptosis (SA) was calculated as SA $(\%)=$ $100 \times(\mathrm{AE}-\mathrm{AC}) /(100-\mathrm{AC})$, where AE equals the percentage of apoptotic cells in the experimental group and $\mathrm{AC}$ equals the percentage of apoptotic cells in the control group. Data are shown as mean $\pm \mathrm{SD}$ $(n=3)$. The data were analyzed by two-sided T-test. ${ }^{*}, p<0.05,{ }^{* *}, p<0.01$. Representative dot-plot images are shown. (D) FOXO1 overexpression inhibits cell cycle progression. Transduced cells were FACS sorted, followed cell cycle analysis by PI staining 2- and 4-days post induction with $100 \mathrm{nM}$ 4-OHT. Data are shown as mean percentage of cells in a cell cycle phase $\pm \operatorname{SD}(n=3)$. The data were analyzed by two-sided T-test. ${ }^{*}, p<0.05,{ }^{* *}, p<0.01$. (E) qRT-PCR analysis of FOXO1 target gene TNSF10. Transduced cells were FACS sorted and RNA was isolated 2 days post induction with $100 \mathrm{nM}$ 4-OHT. qRT-PCR data were quantified by the $2^{-\Delta \Delta C T}$ method. Data are shown as mean \pm SD $(n=3)$. $(\mathrm{F}, \mathrm{G}) \mathrm{BL}$ cell lines were transduced with lentiviral vectors expressing wildtype FOXO1 (F1(WT)) vs. EV control. (F) Transduced cells were FACS sorted 4-5 days post transduction. Expression levels of FOXO1 were analyzed by immunoblot. TUBB served as loading control. A representative of 2 independent experiments is shown. (G) Growth dynamics of transduced BL cell lines. The percentage of GFP Cells $^{+}$ was measured every 3 days using flow cytometry. First measurement was performed $4-5$ days post transduction and the percentage of $\mathrm{GFP}^{+}$cells was set as $100 \%$. Data are shown as mean $\pm \mathrm{SD}(n=3)$.

\section{Discussion}

In the present work, we show that acute genetic depletion of FOXO1 inhibits the proliferation of BL cell lines. In particular, we observed that repression of FOXO1 activated signaling pathways characteristic for the GC LZ program, like the PI3K-AKT and IKK-NF- $\mathrm{KB}$ pathways. This ultimately downregulated the GC DZ program and DZ markers like CXCR4. We identified down-regulation of the proto-oncogene MYB as an important factor contributing to the anti-proliferative effect of FOXO1 knockdown. Importantly, pharmacological repression of FOXO1 also induced cell cycle arrest and apoptosis in BL cell lines and partially reproduced the effects of the shRNA-mediated FOXO1 knockdown on gene transcription. Finally, we demonstrated that overactivation of the FOXO1 activity also induces cell death and growth arrest, indicating the importance of a tight regulation of FOXO1 activity for the survival of BL.

We have shown that knockdown of FOXO1 in BL cell lines either interferes with cell proliferation or the apoptotic program. Recently it has been shown that knockdown of FOXO1 in a MYC/PI3K hyperactivation-driven model of BL in mice induces apoptosis. In BL cell lines, genetic editing of the FOXO1 gene resulted in positive selection of in-frame edited clones, indicating a role of FOXO1 in BL [9]. Therefore, our data support the negative effect of FOXO1 depletion on BL proliferation, but at the same time indicate differences between BL cell lines and the mouse model, especially at the molecular level.

Interestingly, gene expression profiling of BL had revealed the virtual absence of NF- $\mathrm{kB}$ activity [38] and the characteristic expression of markers of the GC DZ program [2,37,44]. We show up-regulation of PI3K-AKT and NF- $\mathrm{KB}$ activity in BL cell lines by FOXO1 depletion. This is in line with higher PI3K-AKT activity in LZ B cells, which also express lower FOXO1 levels than DZ B cells $[5,6]$. FOXO1 has a complex effect on PI3K-AKT activity. Even though PIK3CA, the catalytic subunit of PI3K, was identified as a transcriptional target of FOXOs [45], FOXO1 suppresses PI3K activity in NSCLC cell lines, although the mechanism is unknown [46].

It is conceivable that activation of IKK-NF- $\mathrm{BB}$ contributes to PI3K-AKT activation. The NF- $\mathrm{KB}$ signature is repressed in BL in comparison with ABC- and even with GC-DLBCL [44]. Moreover, NF- $\mathrm{KB}$ activation represses MYC-driven lymphomagenesis and is toxic for BL cell lines [40,47]. Since FOXO3A was shown to inhibit NF- $\mathrm{KB}$ activation [48] by direct binding to RELA [49], it is conceivable that the structurally and functionally related FOXO1 protein acts in a similar way. Being activated, AKT might also contribute to NF- $\mathrm{kB}$ activation by mTORC1-dependent IKK phosphorylation [50]. NF- $\mathrm{kB}$, in turn, can potentiate PI3K-AKT activity, e.g., by suppression of PTEN [51], creating a self-amplifying circuit. Of note, the NF- $\mathrm{kB}$ activating kinases IKKs can inactivate FOXO proteins [52,53], suggesting that the 
efficacy of the FOXO1 depletion might be further increased by IKKs. Thus, FOXO1 acts as a regulator of NF-KB and PI3K-AKT activity in BL and its inhibition results in auto-amplification of IKK-NF- $\mathrm{KB}$ and PI3K-AKT pathways leading to repression of the DZ program.

In accordance with up-regulation of IKK-NF- $\mathrm{kB}$ and PI3K-AKT activity we observed repression of the DZ and up-regulation of the LZ signatures in BL by FOXO1 knockdown. In fact, we saw similar negative effects of FOXO1 knockdown in BL cell lines as previously described for DZ B lymphocytes [6]. Although downregulation of the DZ program by FOXO1 knockdown in a MYC-driven mouse B cell lymphoma model that harbored a constitutively active version of the PI3K catalytic subunit has been recently reported [9], the repertoire of repressed genes was different from what we obtained in human cell lines. Among others, MYB, CCND3, and CXCR4 were not downregulated in the mouse model [9]. We consider repression of the DZ program as the main cause for the cell cycle arrest induced by FOXO1 knockdown.

Due to the complexity of the DZ program, it is difficult to filter out a single factor responsible for the growth arrest. Nevertheless, we identified repression of MYB as an important anti-proliferative event. Of note, MYB is a core BL survival factor, which is highly expressed in centroblasts [26,27]. Importantly, although $M Y B$ is repressed by FOXO1 knockout in mouse GC B cells [6], the binding of FOXO1 to the $M Y B$ promoter was not detected by ChIP-sequencing neither in GC B cells [5], nor in other tissues [30] indicating involvement of other mechanisms (e.g., protein-protein interactions) [54]. Indeed, when we analyzed the effect of pharmacological FOXO1 inhibition we found that induction of miR-150 plays a critical role in regulating MYB levels. In contrast, CXCR4 is a direct FOXO1 transcriptional target [5], which is downregulated by FOXO1 depletion in normal GC B cells [36,37]. Remarkably, we also find a strong repression of CXCR4 by FOXO1 downregulation. Since CXCR4 is also a MYB target [55-57], MYB downregulation might potentiate FOXO1-inactivation induced CXCR4 repression.

We found that the small molecular weight FOXO1 inhibitor AS1842856 is toxic for BL. Although the specificity of small molecular weight inhibitors is a matter of concern in general, the treatment with AS1842856 reproduced most effects of the genetic FOXO1 knockdown, including repression of DZ-specific genes and growth inhibition. Interestingly, most BL cell lines were as sensitive to the inhibitor as BCP-ALL cell lines [21], indicating the existence of common oncogenic mechanisms acting in these B cell neoplasia.

The most obvious differences between shRNA-mediated and pharmacological FOXO1 inactivation were the inability of AS1842856 to repress MYB at mRNA level. Interestingly, repression of MYB protein expression was due to induction of miR-150 transcription. These discrepancies might be explained all by differences in the mechanisms of action. RNA interference decreases the FOXO1 levels, whereas AS1842856 does not modulate FOXO1 expression or localization, instead, AS1842856 binds to the transactivation domain and thereby bona fide interferes with the FOXO1 transactivation activity [42]. It is conceivable that not all interactions of FOXO1 with other proteins might be blocked by AS1842856, moreover the binding specificity of the new structures of AS1842856 might be different. Importantly, AS1842856 binds, although to a lesser extent, to other members of the FOXO family, the effects of whose are only partially redundant [42]. Inhibition of other FOXOs might explain the generally stronger effects of pharmacological in comparison to genetic FOXO1 inhibition in regard to gene expression and PI3K-AKT and NF- $\mathrm{KB}$ activation. Given that NF- $\mathrm{kB}$ directly activates miR-150 transcription [58], it is conceivable that higher NF- $\mathrm{KB}$ activity is responsible for induction of miR-150 by AS1842856. Moreover, since MYB is a recognized NF- $\kappa B$ target [59], strong NF- $\kappa B$ activation by AS1842856 may also block the observed negative effect of FOXO1 depletion on MYB transcription.

Importantly, up-regulation of the $m i R-150$ expression in hematological malignancies is considered a promising therapeutic approach $[60,61]$, warranting further investigations of antitumor effects of FOXO1 inhibitors.

Although FOXO1 inhibitors did not reach clinical trials yet, numerous preclinical in vitro and in vivo studies demonstrated their potential efficacy and safety for the treatment of type 2 diabetes. 
AS1842856, which was discovered to repress FOXO1 dependent transcription of the gluconeogenic enzymes glucose- 6 phosphatase and phosphoenolpyruvate carboxykinase, normalizes blood glucose levels in diabetic but not in healthy mice even at concentrations much higher than therapeutic ones [42]. Similarly, AS1842856 potentiated the regeneration of pancreatic $\beta$-cells and restored insulin secretion in diabetic mice but did neither increase the number of $\beta$-cells nor the insulin concentration in normal mice [62]. Importantly, new selective FOXO1 inhibitors for the treatment of type 2 diabetes have recently been developed by AstraZeneca [63].

The participation of FOXOs in the regulation of different biochemical processes in virtually all systems and organs predetermines high repurposing potential of the FOXO1 inhibitors. With respect to cancer therapy, it has been shown that expression of FOXO transcription factors is essential for maintaining a differential blockade in $40 \%$ of acute myeloid leukemia (AML) cases [64]. Later, FOXO1 was identified as a critical survival factor in AML1-ETO leukemia, which appeared to be highly sensitive to AS1842856. Importantly, CD34 ${ }^{+}$hematopoietic stem and progenitor cells were more than 10-fold less sensitive to AS1842856 than AML pre-leukemic cells and AML cell lines [65]. Finally, in our recent publication we have shown a high sensitivity of BCP-ALL to the genetic and pharmacological depletion of FOXO1. Most important, by using a in vivo BCP-ALL patient-derived xenograft model we demonstrated that AS1842856 induces a significant decrease of tumor load in all critical organ compartments and increases the life span of the animals when administrated at anti-diabetic concentrations [21]. The development of new potent FOXO1 inhibitors could help to increase the efficacy and decrease the toxicity of treatment of FOXO1-dependent tumors including BL.

Paradoxically, FOXO1 overexpression was also inappropriate for BL maintenance. The antitumor effect of FOXO1 activation was also shown in different B cell lymphomas [13,16-18], moreover, for some of them we have provided evidence for a Goldilocks-like (too little is bad as well as too much) behavior of FOXOs [21,23]. Of note, the Goldilocks effect of FOXO1 on cell survival is not restricted to the B cell lineage and has in the meantime been described in other tissues and tumors $[66,67]$.

Overall, we have shown that tight regulation of FOXO1 is critical for BL. In particular, our study highlights a role of FOXO1 as an essential regulator of the DZ survival and proliferation program in BL.

\section{Materials and Methods}

\subsection{Cell Lines}

The BL cell lines (Ramos, BL-41, Namalwa, Daudi, Jiyoye, Raji) and the classical Hodgkin lymphoma (cHL) cell line L-428 were purchased from DSMZ, Braunschweig, Germany. The U-HO1 cell line was generated by one of us (PM) [68]. The culture conditions, analysis of cell line identity, and mycoplasma status were analyzed as described in Supplemental Methods.

\subsection{Vectors and Lentiviral Transduction}

The cell lines were transduced as described in Supplemental Methods. For expression of the shRNA constructs we used the pRSI12-U6-sh-UbiC-TagRFP-2A-Puro lentiviral vector (BioCat, Heidelberg, Germany). For gene expression we used the SF-LV-cDNA-eGFP vector [69]. The FOXO1 knockout with help of the CRISPR/Cas9 vector is described in Supplemental Methods.

\subsection{Immunoblot and $q R T-P C R$}

Immunoblot and qRT-PCR were done as described in Supplemental Methods. Primer sequences and antibodies are listed in Supplemental Methods.

\subsection{Flow Cytometry, Cell Sorting, and Cell Viability Analysis}

Growth dynamics of cell lines transduced with lentiviral vectors expressing RFP or GFP were monitored by flow cytometry (FACSCanto II, BD Biosciences, San Jose, CA, USA). For biochemical analysis, $\mathrm{RFP}^{+}$or $\mathrm{GFP}^{+}$cells were sorted using a FACSAria (BD Biosciences) by the Core Facility 
"Fluorescent Activated Cell Sorting," Medical Faculty of Ulm, Germany or using the S3e Cell Sorter (Bio-Rad, Hercules, CA, USA). Cell cycle distribution was also measured by flow cytometry using propidium iodide (PI) and cell death was measured by Annexin-V-FITC/PI or Annexin-V-APC/PI staining, as we described previously [20]. CXCR4 surface and intracellular FOXO1 staining was measured using the flow cytometer FACSCanto (BD Biosciences). The sensitivity of the cell lines to the FOXO1 inhibitor was assessed by MTT test. IC50 was calculated by fitting the data points to a nonlinear regression curve using GraphPad Prism (GraphPad Software, San Diego, CA, USA).

\subsection{Gene Expression Profiling (GEP) and Gene Set Enrichment Analysis (GSEA)}

Total RNA was extracted from sorted cells 4 days post transduction with F1sh or scrambled control and gene expression profiles were analyzed using Human Gene 1.0 ST Affymetrix GeneChip arrays by the Core Facility Genomics (University of Ulm) as we described previously [18]. Probe-level data were obtained using the robust multichip average (RMA) normalization algorithm. The analysis of differentially expressed genes was achieved with help of GeneSifter microarray data analysis software (www.genesifter.net, PerkinElmer; Waltham, MA, USA). For all cell lines and conditions, two biological replicates were analyzed. To identify pathways significantly modulated by FOXO1 depletion we used GSEA (http://software.broadinstitute.org/gsea/index.jsp, 04.07.2016). Microarray data have been deposited in the NCBI GEO (http://www.ncbi.nlm.nih.gov/gds) under the accession number GSE109911.

\subsection{Statistical Analysis}

The data were analyzed by two-tailed Student's $t$-test analysis (Microsoft Excel).

\section{Conclusions}

We found that tight regulation of FOXO1 is essential for the survival of BL cell lines and identified maintenance of the DZ B cell survival and proliferation program as the main cause of BL dependency on FOXO1 expression.

Supplementary Materials: The following are available online at http://www.mdpi.com/2072-6694/11/10/ 1427/s1, Figure S1: Nuclear localization of FOXO1 in BL cell lines and tumors, Figure S2: Validation of CRISPR/Cas9-mediated FOXO1 knockout in BL cell lines, Figure S3: CCND3 overexpression cannot rescue BL cells from the toxic effect of FOXO1 knockdown, Figure S4: FOXO1 knockdown does not induce oxidative stress or mitophagy, Figure S5: FOXO1 knockdown represses the dark zone signature, proliferation associated signatures and FOXO1 target genes of germinal center dark zone B cells, Figure S6: MYB expression partially rescues the FOXO1-knockdown induced G1 cell cycle arrest, Table S1: N-terminal FOXO1 hotspot mutations in BL cell lines, Table S2: Genes identified by Human Gene 1.0 ST Affymetrix GeneChip array modulated by FOXO1 knockdown more than 1.5 fold in both BL cell lines (centered Pearson correlation, coefficient 0.98), Table S3: Genes identified by Human Gene 1.0 ST Affymetrix GeneChip array modulated by FOXO1 knockdown more than 1.5 fold in least at one of two BL cell lines (adjusted $p<0.05$; statistics: ANOVA, correction: Benjamini and Hochberg), Table S4: The core-enriched genes in "Genes modulated by FOXO1 knockdown more than 1.5 fold at least in one of two BL cell lines", Table S5: The core-enriched genes in "Genes modulated by FOXO1 knockdown more than 1.5 fold at least in one of two BL cell lines", Table S6: The core-enriched genes in "Genes modulated by FOXO1 knockdown more than 1.5 fold at least in one of two BL cell lines", Table S7: The core-enriched genes in "Genes modulated by FOXO1 knockdown more than 1.5 fold at least in one of two BL cell lines", Table S8: The core-enriched genes in "Genes modulated by FOXO1 knockdown more than 1.5 fold at least in one of two BL cell lines", Table S9: The core-enriched genes in "Genes modulated by FOXO1 knockdown more than 1.5 fold at least in one of two BL cell lines", Table S10: The core-enriched genes in "Genes modulated by FOXO1 knockdown more than 1.5 fold at least in one of two BL cell lines", Table S11: The core-enriched genes in "Genes modulated by FOXO1 knockdown more than 1.5 fold at least in one of two BL cell lines", Table S12: The core-enriched genes in "Genes modulated by FOXO1 knockdown more than 1.5 fold at least in one of two BL cell lines", Table S13: The core-enriched genes in "Genes modulated by FOXO1 knockdown more than 1.5 fold at least in one of two BL cell lines", Table S14: The core-enriched genes in "Genes modulated by FOXO1 knockdown more than 1.5 fold at least in one of two BL cell lines", Table S15: The core-enriched genes in "Genes modulated by FOXO1 knockdown more than 1.5 fold at least in one of two BL cell lines", Table S16: The core-enriched genes in "Genes modulated by FOXO1 knockdown more than 1.5 fold at least in one of two BL cell lines", Table S17: The core-enriched genes in "Genes modulated by FOXO1 knockdown more than 1.5 fold at least in one of two BL cell lines", Table S18: Gene signature of downregulated genes after MYB knockdown in BL cell line ST486, Table S19: Gene signatures of essential genes in 
two Burkitt lymphoma cell lines, Table S20: Gene signatures of FOXO1 target genes in human germinal center B cells as well as FOXO1 target genes upregulated in DZ vs. LZ cells or vice versa.

Author Contributions: Performed research and analyzed data: F.G., S.EW., L.JYMS., A.U. Designed research and wrote the manuscript: F.G., T.W., A.U., P.M.

Funding: Franziska Gehringer was supported by the International Graduate School in Molecular Medicine, Ulm. This work was supported by Deutsche Krebshilfe eV (grant 110564) (Thomas Wirth., Alexey Ushmorov.)

Acknowledgments: We are thankful to R. Siebert and R. Wagener (Institute of Human Genetics, Ulm University) for the bioinformatic help in the course of the project and A. van den Berg and J. Kluiver (Department of Pathology and Medical Biology, University of Groningen, NL) for the help with the design and analysis of the microRNA experiments. The authors thank Anita Kick for excellent technical assistance. We thank the Core Facility FACS (Medical Faculty, University of Ulm) for cell sorting, K. Holzmann (Core Facility Genomics) for microarray analysis, Michaela Buck and Elena Kelsch (Institute of Pathology, University of Ulm) for STR analysis, and Kevin Mellert (Institute of Pathology, University of Ulm) for BL cell lines.

Conflicts of Interest: The authors declare no competing financial interests.

\section{References}

1. Schmitz, R.; Ceribelli, M.; Pittaluga, S.; Wright, G.; Staudt, L.M. Oncogenic mechanisms in Burkitt lymphoma. Cold Spring Harb. Perspect. Med. 2014, 4. [CrossRef] [PubMed]

2. Kretzmer, H.; Bernhart, S.H.; Wang, W.; Haake, A.; Weniger, M.A.; Bergmann, A.K.; Betts, M.J.; Carrillo-de-Santa-Pau, E.; Doose, G.; Gutwein, J.; et al. DNA methylome analysis in Burkitt and follicular lymphomas identifies differentially methylated regions linked to somatic mutation and transcriptional control. Nat. Genet. 2015, 47, 1316-1325. [CrossRef] [PubMed]

3. Swerdlow, S.H.; Campo, E.; Pileri, S.A.; Harris, N.L.; Stein, H.; Siebert, R.; Advani, R.; Ghielmini, M.; Salles, G.A.; Zelenetz, A.D.; et al. The 2016 revision of the World Health Organization classification of lymphoid neoplasms. Blood 2016, 127, 2375-2390. [CrossRef] [PubMed]

4. De Silva, N.S.; Klein, U. Dynamics of B cells in germinal centres. Nat. Rev. Immunol. 2015, 15, 137-148. [CrossRef] [PubMed]

5. Dominguez-Sola, D.; Kung, J.; Holmes, A.B.; Wells, V.A.; Mo, T.; Basso, K.; Dalla-Favera, R. The FOXO1 Transcription Factor Instructs the Germinal Center Dark Zone Program. Immunity 2015, 43, 1064-1074. [CrossRef]

6. Sander, S.; Chu, V.T.; Yasuda, T.; Franklin, A.; Graf, R.; Calado, D.P.; Li, S.; Imami, K.; Selbach, M.; Di Virgilio, M.; et al. PI3 Kinase and FOXO1 Transcription Factor Activity Differentially Control B Cells in the Germinal Center Light and Dark Zones. Immunity 2015, 43, 1075-1086. [CrossRef] [PubMed]

7. Dominguez-Sola, D.; Victora, G.D.; Ying, C.Y.; Phan, R.T.; Saito, M.; Nussenzweig, M.C.; Dalla-Favera, R. The proto-oncogene MYC is required for selection in the germinal center and cyclic reentry. Nat. Immunol. 2012, 13, 1083-1091. [CrossRef]

8. Loeffler-Wirth, H.; Kreuz, M.; Hopp, L.; Arakelyan, A.; Haake, A.; Cogliatti, S.B.; Feller, A.C.; Hansmann, M.L.; Lenze, D.; Moller, P.; et al. A modular transcriptome map of mature B cell lymphomas. Genome Med. 2019, 11, 27. [CrossRef]

9. Kabrani, E.; Chu, V.T.; Tasouri, E.; Sommermann, T.; Bassler, K.; Ulas, T.; Zenz, T.; Bullinger, L.; Schultze, J.; Rajewsky, K.; et al. Nuclear FOXO1 promotes lymphomagenesis in germinal center B cells. Blood 2018. [CrossRef]

10. Schmitz, R.; Young, R.M.; Ceribelli, M.; Jhavar, S.; Xiao, W.; Zhang, M.; Wright, G.; Shaffer, A.L.; Hodson, D.J.; Buras, E.; et al. Burkitt lymphoma pathogenesis and therapeutic targets from structural and functional genomics. Nature 2012, 490, 116-120. [CrossRef]

11. Love, C.; Sun, Z.; Jima, D.; Li, G.; Zhang, J.; Miles, R.; Richards, K.L.; Dunphy, C.H.; Choi, W.W.; Srivastava, G.; et al. The genetic landscape of mutations in Burkitt lymphoma. Nat. Genet. 2012, 44, 1321-1325. [CrossRef] [PubMed]

12. Richter, J.; Schlesner, M.; Hoffmann, S.; Kreuz, M.; Leich, E.; Burkhardt, B.; Rosolowski, M.; Ammerpohl, O.; Wagener, R.; Bernhart, S.H.; et al. Recurrent mutation of the ID3 gene in Burkitt lymphoma identified by integrated genome, exome and transcriptome sequencing. Nat. Genet. 2012, 44, 1316-1320. [CrossRef] [PubMed]

13. Calnan, D.R.; Brunet, A. The FoxO code. Oncogene 2008, 27, 2276-2288. [CrossRef] [PubMed] 
14. Eijkelenboom, A.; Burgering, B.M. FOXOs: Signalling integrators for homeostasis maintenance. Nat. Rev. Mol. Cell Biol. 2013, 14, 83-97. [CrossRef] [PubMed]

15. Ryu, K.J.; Park, C.; Hong, M.; Ko, Y.H.; Kim, W.S.; Kim, S.J. FOXO4 expression is related to stem cell-like properties and resistance to treatment in diffuse large B cell lymphoma. Oncotarget 2017, 8, 2466-2476. [CrossRef] [PubMed]

16. Kohrer, S.; Havranek, O.; Seyfried, F.; Hurtz, C.; Coffey, G.P.; Kim, E.; Ten Hacken, E.; Jager, U.; Vanura, K.; O'Brien, S.; et al. Pre-BCR signaling in precursor B cell acute lymphoblastic leukemia regulates PI3K/AKT, FOXO1 and MYC, and can be targeted by SYK inhibition. Leukemia 2016, 30, 1246-1254. [CrossRef] [PubMed]

17. Szydlowski, M.; Kiliszek, P.; Sewastianik, T.; Jablonska, E.; Bialopiotrowicz, E.; Gorniak, P.; Polak, A.; Markowicz, S.; Nowak, E.; Grygorowicz, M.A.; et al. FOXO1 activation is an effector of SYK and AKT inhibition in tonic BCR signal-dependent diffuse large B cell lymphomas. Blood 2016, 127, 739-748. [CrossRef] [PubMed]

18. Vogel, M.J.; Xie, L.; Guan, H.; Tooze, R.M.; Maier, T.; Kostezka, U.; Maier, H.J.; Holzmann, K.; Chan, F.C.; Steidl, C.; et al. FOXO1 repression contributes to block of plasma cell differentiation in classical Hodgkin lymphoma. Blood 2014, 124, 3118-3129. [CrossRef] [PubMed]

19. Zhou, P.; Blain, A.E.; Newman, A.M.; Zaka, M.; Chagaluka, G.; Adlar, F.R.; Offor, U.T.; Broadbent, C.; Chaytor, L.; Whitehead, A.; et al. Sporadic and endemic Burkitt lymphoma have frequent FOXO1 mutations but distinct hotspots in the AKT recognition motif. Blood Adv. 2019, 3, 2118-2127. [CrossRef]

20. Xie, L.; Ushmorov, A.; Leithauser, F.; Guan, H.; Steidl, C.; Farbinger, J.; Pelzer, C.; Vogel, M.J.; Maier, H.J.; Gascoyne, R.D.; et al. FOXO1 is a tumor suppressor in classical Hodgkin lymphoma. Blood 2012, 119, 3503-3511. [CrossRef]

21. Wang, F.; Demir, S.; Gehringer, F.; Osswald, C.D.; Seyfried, F.; Enzenmuller, S.; Eckhoff, S.M.; Maier, T.; Holzmann, K.; Debatin, K.M.; et al. Tight regulation of FOXO1 is essential for maintenance of B cell precursor acute lymphoblastic leukemia. Blood 2018. [CrossRef] [PubMed]

22. Matkar, S.; Sharma, P.; Gao, S.; Gurung, B.; Katona, B.W.; Liao, J.; Muhammad, A.B.; Kong, X.C.; Wang, L.; Jin, G.; et al. An Epigenetic Pathway Regulates Sensitivity of Breast Cancer Cells to HER2 Inhibition via FOXO/c-Myc Axis. Cancer Cell 2015, 28, 472-485. [CrossRef] [PubMed]

23. Osswald, C.D.; Xie, L.; Guan, H.; Herrmann, F.; Pick, S.M.; Vogel, M.J.; Gehringer, F.; Chan, F.C.; Steidl, C.; Wirth, T.; et al. Fine tuning of FOXO3A in cHL as a survival mechanism and a hallmark of abortive plasma cell differentiation. Blood 2018. [CrossRef] [PubMed]

24. Amin, R.H.; Schlissel, M.S. Foxo1 directly regulates the transcription of recombination-activating genes during B cell development. Nat. Immunol. 2008, 9, 613-622. [CrossRef] [PubMed]

25. Schneider, C.; Setty, M.; Holmes, A.B.; Maute, R.L.; Leslie, C.S.; Mussolin, L.; Rosolen, A.; Dalla-Favera, R.; Basso, K. MicroRNA 28 controls cell proliferation and is down-regulated in B cell lymphomas. Proc. Natl. Acad. Sci. USA 2014, 111, 8185-8190. [CrossRef] [PubMed]

26. Joshi, S.; Wu, A.; Verbik, D.; Algarra, S.; Bishop, M.; Pirruccello, S.; Iversen, P.; Jackson, J.; Kessinger, M.; Sharp, J. Oligonucleotides complementary to c-myb messenger RNA inhibit growth and induce apoptosis in human Burkitt lymphoma cells. Int. J. Oncol. 1996, 8, 815-820. [CrossRef] [PubMed]

27. Lefebvre, C.; Rajbhandari, P.; Alvarez, M.J.; Bandaru, P.; Lim, W.K.; Sato, M.; Wang, K.; Sumazin, P.; Kustagi, M.; Bisikirska, B.C.; et al. A human B cell interactome identifies MYB and FOXM1 as master regulators of proliferation in germinal centers. Mol. Syst. Biol. 2010, 6, 377. [CrossRef]

28. Ricke, R.M.; Jeganathan, K.B.; van Deursen, J.M. Bub1 overexpression induces aneuploidy and tumor formation through Aurora B kinase hyperactivation. J. Cell Biol. 2011, 193, 1049-1064. [CrossRef]

29. Zhang, T.; Kim, D.H.; Xiao, X.; Lee, S.; Gong, Z.; Muzumdar, R.; Calabuig-Navarro, V.; Yamauchi, J.; Harashima, H.; Wang, R.; et al. FoxO1 Plays an Important Role in Regulating beta-Cell Compensation for Insulin Resistance in Male Mice. Endocrinology 2016, 157, 1055-1070. [CrossRef]

30. Webb, A.E.; Kundaje, A.; Brunet, A. Characterization of the direct targets of FOXO transcription factors throughout evolution. Aging Cell 2016, 15, 673-685. [CrossRef]

31. Eguchi, J.; Wang, X.; Yu, S.; Kershaw, E.E.; Chiu, P.C.; Dushay, J.; Estall, J.L.; Klein, U.; Maratos-Flier, E.; Rosen, E.D. Transcriptional control of adipose lipid handling by IRF4. Cell Metab. 2011, 13, $249-259$. [CrossRef] [PubMed] 
32. Webb, A.E.; Pollina, E.A.; Vierbuchen, T.; Urban, N.; Ucar, D.; Leeman, D.S.; Martynoga, B.; Sewak, M.; Rando, T.A.; Guillemot, F.; et al. FOXO3 shares common targets with ASCL1 genome-wide and inhibits ASCL1-dependent neurogenesis. Cell Rep. 2013, 4, 477-491. [CrossRef] [PubMed]

33. Wang, T.; Birsoy, K.; Hughes, N.W.; Krupczak, K.M.; Post, Y.; Wei, J.J.; Lander, E.S.; Sabatini, D.M. Identification and characterization of essential genes in the human genome. Science 2015, 350, 1096-1101. [CrossRef] [PubMed]

34. O'Rourke, J.P.; Ness, S.A. Alternative RNA splicing produces multiple forms of c-Myb with unique transcriptional activities. Mol. Cell Biol. 2008, 28, 2091-2101. [CrossRef] [PubMed]

35. Doulatov, S.; Vo, L.T.; Chou, S.S.; Kim, P.G.; Arora, N.; Li, H.; Hadland, B.K.; Bernstein, I.D.; Collins, J.J.; Zon, L.I.; et al. Induction of multipotential hematopoietic progenitors from human pluripotent stem cells via respecification of lineage-restricted precursors. Cell Stem Cell 2013, 13, 459-470. [CrossRef] [PubMed]

36. Caron, G.; Le Gallou, S.; Lamy, T.; Tarte, K.; Fest, T. CXCR4 expression functionally discriminates centroblasts versus centrocytes within human germinal center B cells. J. Immunol. 2009, 182, 7595-7602. [CrossRef] [PubMed]

37. Victora, G.D.; Dominguez-Sola, D.; Holmes, A.B.; Deroubaix, S.; Dalla-Favera, R.; Nussenzweig, M.C. Identification of human germinal center light and dark zone cells and their relationship to human B cell lymphomas. Blood 2012, 120, 2240-2248. [CrossRef] [PubMed]

38. Hummel, M.; Bentink, S.; Berger, H.; Klapper, W.; Wessendorf, S.; Barth, T.F.; Bernd, H.W.; Cogliatti, S.B.; Dierlamm, J.; Feller, A.C.; et al. A biologic definition of Burkitt's lymphoma from transcriptional and genomic profiling. N. Engl. J. Med. 2006, 354, 2419-2430. [CrossRef]

39. Kennedy, J.E.; Marchese, A. Regulation of GPCR Trafficking by Ubiquitin. Prog. Mol. Biol. Transl. Sci. 2015, 132, 15-38. [CrossRef]

40. Klapproth, K.; Sander, S.; Marinkovic, D.; Baumann, B.; Wirth, T. The IKK2/NF-кB pathway suppresses MYC-induced lymphomagenesis. Blood 2009, 114, 2448-2458. [CrossRef]

41. Maier, H.J.; Marienfeld, R.; Wirth, T.; Baumann, B. Critical role of RelB serine 368 for dimerization and p100 stabilization. J. Biol. Chem. 2003, 278, 39242-39250. [CrossRef] [PubMed]

42. Nagashima, T.; Shigematsu, N.; Maruki, R.; Urano, Y.; Tanaka, H.; Shimaya, A.; Shimokawa, T.; Shibasaki, M. Discovery of novel forkhead box O1 inhibitors for treating type 2 diabetes: Improvement of fasting glycemia in diabetic db/db mice. Mol. Pharm. 2010, 78, 961-970. [CrossRef]

43. Dzikiewicz-Krawczyk, A.; Kok, K.; Slezak-Prochazka, I.; Robertus, J.L.; Bruining, J.; Tayari, M.M.; Rutgers, B.; de Jong, D.; Koerts, J.; Seitz, A.; et al. ZDHHC11 and ZDHHC11B are critical novel components of the oncogenic MYC-miR-150-MYB network in Burkitt lymphoma. Leukemia 2017, 31, 1470-1473. [CrossRef] [PubMed]

44. Dave, S.S.; Fu, K.; Wright, G.W.; Lam, L.T.; Kluin, P.; Boerma, E.J.; Greiner, T.C.; Weisenburger, D.D.; Rosenwald, A.; Ott, G.; et al. Molecular diagnosis of Burkitt's lymphoma. N. Engl. J. Med. 2006, 354, 2431-2442. [CrossRef] [PubMed]

45. Hui, R.C.; Gomes, A.R.; Constantinidou, D.; Costa, J.R.; Karadedou, C.T.; Fernandez de Mattos, S.; Wymann, M.P.; Brosens, J.J.; Schulze, A.; Lam, E.W. The forkhead transcription factor FOXO3a increases phosphoinositide-3 kinase/Akt activity in drug-resistant leukemic cells through induction of PIK3CA expression. Mol. Cell Biol. 2008, 28, 5886-5898. [CrossRef] [PubMed]

46. Wang, C.; Liu, E.; Li, W.; Cui, J.; Li, T. MiR-3188 Inhibits Non-small Cell Lung Cancer Cell Proliferation through FOXO1-Mediated mTOR-p-PI3K/AKT-c-JUN Signaling Pathway. Front. Pharm. 2018, 9, 1362. [CrossRef] [PubMed]

47. Guan, H.; Xie, L.; Klapproth, K.; Weitzer, C.D.; Wirth, T.; Ushmorov, A. Decitabine represses translocated MYC oncogene in Burkitt lymphoma. J. Pathol. 2013, 229, 775-783. [CrossRef] [PubMed]

48. Lin, L.; Hron, J.D.; Peng, S.L. Regulation of NF-кB, Th activation, and autoinflammation by the forkhead transcription factor Foxo3a. Immunity 2004, 21, 203-213. [CrossRef] [PubMed]

49. Thompson, M.G.; Larson, M.; Vidrine, A.; Barrios, K.; Navarro, F.; Meyers, K.; Simms, P.; Prajapati, K.; Chitsike, L.; Hellman, L.M.; et al. FOXO3-NF-кB RelA Protein Complexes Reduce Proinflammatory Cell Signaling and Function. J. Immunol. 2015, 195, 5637-5647. [CrossRef]

50. Dan, H.C.; Cooper, M.J.; Cogswell, P.C.; Duncan, J.A.; Ting, J.P.; Baldwin, A.S. Akt-dependent regulation of NF-kB is controlled by mTOR and Raptor in association with IKK. Genes Dev. 2008, 22, 1490-1500. [CrossRef] 
51. Vasudevan, K.M.; Gurumurthy, S.; Rangnekar, V.M. Suppression of PTEN expression by NF-k B prevents apoptosis. Mol. Cell Biol. 2004, 24, 1007-1021. [CrossRef]

52. Hu, M.C.; Lee, D.F.; Xia, W.; Golfman, L.S.; Ou-Yang, F.; Yang, J.Y.; Zou, Y.; Bao, S.; Hanada, N.; Saso, H.; et al. IKB kinase promotes tumorigenesis through inhibition of forkhead FOXO3a. Cell 2004, 117, 225-237. [CrossRef]

53. Huang, H.; Tindall, D.J. Regulation of FOXO protein stability via ubiquitination and proteasome degradation. Biochim. Biophys. Acta 2011, 1813, 1961-1964. [CrossRef] [PubMed]

54. Huang, Y.; Gao, M.; Yang, F.; Zhang, L.; Su, Z. Deciphering the promiscuous interactions between intrinsically disordered transactivation domains and the KIX domain. Proteins 2017, 85, 2088-2095. [CrossRef] [PubMed]

55. Quintana, A.M.; Zhou, Y.E.; Pena, J.J.; O’Rourke, J.P.; Ness, S.A. Dramatic repositioning of c-Myb to different promoters during the cell cycle observed by combining cell sorting with chromatin immunoprecipitation. PLoS ONE 2011, 6, e17362. [CrossRef] [PubMed]

56. Quintana, A.M.; Liu, F.; O'Rourke, J.P.; Ness, S.A. Identification and regulation of c-Myb target genes in MCF-7 cells. BMC Cancer 2011, 11, 30. [CrossRef] [PubMed]

57. Liu, F.; Lei, W.; O'Rourke, J.P.; Ness, S.A. Oncogenic mutations cause dramatic, qualitative changes in the transcriptional activity of c-Myb. Oncogene 2006, 25, 795-805. [CrossRef]

58. Wang, N.; Zhou, Z.; Wu, T.; Liu, W.; Yin, P.; Pan, C.; Yu, X. TNF-alpha-induced NF-kB activation upregulates microRNA-150-3p and inhibits osteogenesis of mesenchymal stem cells by targeting beta-catenin. Open Biol. 2016, 6, 150258. [CrossRef]

59. Toth, C.R.; Hostutler, R.F.; Baldwin, A.S., Jr.; Bender, T.P. Members of the nuclear factor $\kappa \mathrm{B}$ family transactivate the murine c-myb gene. J. Biol. Chem. 1995, 270, 7661-7671. [CrossRef]

60. He, Y.; Jiang, X.; Chen, J. The role of miR-150 in normal and malignant hematopoiesis. Oncogene 2013, 33, 3887. [CrossRef]

61. Musilova, K.; Mraz, M. MicroRNAs in B-cell lymphomas: how a complex biology gets more complex. Leukemia 2014, 29, 1004. [CrossRef]

62. Chera, S.; Baronnier, D.; Ghila, L.; Cigliola, V.; Jensen, J.N.; Gu, G.; Furuyama, K.; Thorel, F.; Gribble, F.M.; Reimann, F.; et al. Diabetes recovery by age-dependent conversion of pancreatic delta-cells into insulin producers. Nature 2014, 514, 503-507. [CrossRef] [PubMed]

63. Langlet, F.; Haeusler, R.A.; Linden, D.; Ericson, E.; Norris, T.; Johansson, A.; Cook, J.R.; Aizawa, K.; Wang, L.; Buettner, C.; et al. Selective Inhibition of FOXO1 Activator/Repressor Balance Modulates Hepatic Glucose Handling. Cell 2017, 171, 824-835.e818. [CrossRef] [PubMed]

64. Sykes, S.M.; Lane, S.W.; Bullinger, L.; Kalaitzidis, D.; Yusuf, R.; Saez, B.; Ferraro, F.; Mercier, F.; Singh, H.; Brumme, K.M.; et al. AKT/FOXO signaling enforces reversible differentiation blockade in myeloid leukemias. Cell 2011, 146, 697-708. [CrossRef] [PubMed]

65. Lin, S.; Ptasinska, A.; Chen, X.; Shrestha, M.; Assi, S.A.; Chin, P.S.; Imperato, M.R.; Aronow, B.J.; Zhang, J.; Weirauch, M.T.; et al. A FOXO1-induced oncogenic network defines the AML1-ETO preleukemic program. Blood 2017, 130, 1213-1222. [CrossRef] [PubMed]

66. Dharaneeswaran, H.; Abid, M.R.; Yuan, L.; Dupuis, D.; Beeler, D.; Spokes, K.C.; Janes, L.; Sciuto, T.; Kang, P.M.; Jaminet, S.S.; et al. FOXO1-mediated activation of Akt plays a critical role in vascular homeostasis. Circ. Res. 2014, 115, 238-251. [CrossRef]

67. Hornsveld, M.; Smits, L.M.; Meerlo, M.; van Amersfoort, M.; Groot Koerkamp, M.J.; van Leenen, D.; Kloet, D.E.; Holstege, F.C.; Derksen, P.W.B.; Burgering, B.M.T.; et al. FOXO transcription factors both suppress and support breast cancer progression. Cancer Res. 2018. [CrossRef] [PubMed]

68. Mader, A.; Bruderlein, S.; Wegener, S.; Melzner, I.; Popov, S.; Muller-Hermelink, H.K.; Barth, T.F.; Viardot, A.; Moller, P. U-HO1, a new cell line derived from a primary refractory classical Hodgkin lymphoma. Cytogenet. Genome Res. 2007, 119, 204-210. [CrossRef] [PubMed]

69. Wang, J.; Sun, Q.; Morita, Y.; Jiang, H.; Gross, A.; Lechel, A.; Hildner, K.; Guachalla, L.M.; Gompf, A.; Hartmann, D.; et al. A differentiation checkpoint limits hematopoietic stem cell self-renewal in response to DNA damage. Cell 2012, 148, 1001-1014. [CrossRef] [PubMed]

(C) 2019 by the authors. Licensee MDPI, Basel, Switzerland. This article is an open access article distributed under the terms and conditions of the Creative Commons Attribution (CC BY) license (http://creativecommons.org/licenses/by/4.0/). 